\title{
What do price discovery metrics really measure?
}

\author{
Tālis J. Putninšs * \\ University of Technology Sydney, PO Box 123 Broadway, NSW 2007, Australia \\ Stockholm School of Economics in Riga, Strelnieku iela 4a, Riga LV-1010, Latvia
}

Forthcoming, Journal of Empirical Finance

\begin{abstract}
A market is typically considered to dominate price discovery if it is the first to reflect new information about the fundamental value. Our simulations indicate that common price discovery metrics - Hasbrouck information share and Harris-McInish-Wood component share - are only consistent with this view of price discovery if the price series have equal levels of noise, including microstructure frictions and liquidity. If the noise in the price series differs, the information and component shares measure a combination of leadership in impounding new information and relative avoidance of noise, to varying degrees. A third price discovery metric, the 'information leadership share' uses the information share and the component share together to identify the price series that is first to impound new information. This third metric is robust to differences in noise levels and therefore correctly attributes price discovery in a wider range of settings. Using four recent empirical studies of price discovery we show that the choice and interpretation of price discovery metrics can have a substantial impact on conclusions about price discovery.
\end{abstract}

JEL classification: G14

Keywords: price discovery, information share, component share, information leadership share

\footnotetext{
*Email: talis.putnins@uts.edu.au.

The author is grateful to three anonymous referees for helpful comments.
} 


\section{Introduction}

Price discovery, a fundamentally important role of secondary markets, is the "efficient and timely incorporation of the information implicit in investor trading into market prices" (Lehmann, 2002, p. 259). When multiple price series are related via a common asset (e.g., a stock trading in multiple venues, order flow for one security from different market participants, and different derivative securities linked to the same underlying asset) the contribution of a price series to price discovery is typically considered to be the extent to which it is the first to reflect new information about the 'true' underlying asset value. There are two main (occasionally competing) empirical measures of the contribution of different price series to price discovery: Hasbrouck information share (IS) and Harris-McInish-Wood component share (CS). ${ }^{1}$ Market microstructure scholars have made substantial progress in reconciling and understanding the two measures (e.g., Baillie et al., 2002; Lehman, 2002). In a recent and notable contribution to this effort, Yan and Zivot (2010) analytically show how to interpret $I S$ and $C S$ in the context of a structural cointegration model.

Despite the substantial progress made to date, there is still not a consensus in practice on what each metric really measures. Consequently, the approach to applying and interpreting the metrics in different applications is far from consistent. ${ }^{2}$ Furthermore, Yan and Zivot (2010) propose combining $I S$ and $C S$ to specifically measure impounding of new information, and the usefulness of this technique is yet to be thoroughly tested.

This article aims to illustrate what each of the price discovery metrics really measures, in the hope of promoting a more consistent approach to their use and interpretation. We do this by estimating each price discovery metric on simulated data for a simple structural model, choosing parameter values and sample size to mimic an empirical research setting. A key feature of the model is that it allows price series to differ in two important ways: (i) noise (e.g., microstructure frictions such as tick

\footnotetext{
${ }^{1}$ For a good review of $I S$ and $C S$ and how they are related see Baillie et al. (2002), Lehman (2002) and Yan and Zivot (2010). The next section provides a brief overview of these metrics. We refer to $C S$ as the Harris-McInish-Wood component share due to their role in popularizing this measure of price discovery, but we note that others were involved in pioneering the use of this metric to measure price discovery (e.g., Booth et al., 1999; Chu et al., 1999).

${ }^{2}$ For example, see recent studies such as Chen and Gau (2010), Frijns et al. (2010), Korczak and Phylaktis (2010), Anand et al. (2011), Fricke and Menkhoff (2011), Liu and An (2011), Chen and Chung (2012), Chen and Sub Choi (2012), Rittler (2012), and Chen et al. (2013).
} 
discreteness and bid-ask bounce); and (ii) speed of adjustment to new information. The interaction of these two dimensions is the source of much of the confusion and debate about the different price discovery metrics. By varying each of these two characteristics independently we obtain a two-dimensional grid of parameters describing the relations between two price series, i.e., relative to the reference price series, a price series of interest can be: (i) noisier and slower; (ii) noisier and faster; (iii) less noisy and slower; or (iv) less noisy and faster. By estimating all of the price discovery metrics for each of these cases (and many values in between) we demonstrate what each metric actually measures and thus how the price discovery metrics should be interpreted with respect to the relative amount of noise and speed of incorporation of information.

We find that $I S$ and $C S$ only accurately measure contribution to price discovery, in the conventional sense of being the first to reflect innovations in the fundamental value, when the price series being compared have a similar level of noise. When the levels of noise differ both $I S$ and $C S$ measure to varying extents: (i) the relative speed at which a price impounds new information; and (ii) the relative avoidance of noise. That is, price series that reflect new information faster will tend to have higher $I S$ and $C S$, but so too will price series that are less noisy, holding constant the speed with which information is impounded. When the difference in noise levels is sufficiently large relative to the differences in the speed at which information is impounded, conventional interpretations of $I S$ and $C S$ can lead to incorrect conclusions about which price series incorporates information first. For example, in a two-market setting $I S$ and $C S$ could be larger (greater than $50 \%$ ) for the market that is slower to incorporate new information as long as it is sufficiently less noisy. Our simulations indicate that $I S$ places greater weight on the speed at which a price series impounds information compared to the $C S$ metric.

In contrast, an adaptation of an expression derived by Yan and Zivot (2010), which we call the 'informational leadership share' (ILS), is able to correctly attribute contributions to price discovery in the presence of different levels of noise. This metric, which is only applicable in bivariate systems, uses $I S$ and $C S$ together to identify the price series that leads the process of impounding new information.

We illustrate the practical importance of the choice and interpretation of the price discovery metric using four recent empirical price discovery studies. For the four studies 
we calculate ILS and compare the conclusions from this metric with those made by the studies. The results are striking: in many cases ILS leads to opposite conclusions to those made by the studies. For example, Rittler (2012) concludes that futures contracts dominate price discovery in the EU emission trading market and that their dominance has increased through time, whereas ILS indicates the opposite: the spot market leads price discovery overall, and the contribution of the futures market to price discovery is in fact declining through time. The differences in conclusions stem from the failure of many empirical price discovery studies to account for the way $I S$ and $C S$ are affected by differences in noise levels across the price series of interest. We discuss several implications of our findings for existing and future research.

The present paper complements Yan and Zivot (2010) by using Monte Carlo simulations to illustrate the insights that Yan and Zivot provide analytically, and also provides some extensions and novel insights. We design our simulations and choose parameter values to mimic an empirical setting in order to demonstrate the relevance of the analytic results for empirical work. Another reason for turning to simulations is that the structural cointegration specifications implied by our models of price formation are not invertible and therefore we cannot perform the analytic exercise that is done by Yan and Zivot. An advantage of our structural models, in addition to being simple and intuitive, is that each of the two price series has an independent source of noise (trading frictions) rather than sharing one transitory shock, which we argue is a realistic feature in many price discovery applications. A further advantage is that we are able to provide evidence on how Yan and Zivot's results and measure of informational leadership hold up in a model of price formation that does not satisfy the assumptions under which Yan and Zivot derived their results. Interestingly, the measure of informational leadership reliably attributes price discovery in our setting, suggesting it is also useful in at least some models of price formation that do not satisfy Yan and Zivot's assumptions. We do not know whether this holds for other models of price formation. We also document some differences from Yan and Zivot's analytic results. For example, our simulations indicate that $C S$ measures to some extent the relative speed at which a price series impounds new information, not just the relative avoidance of noise as documented by Yan and Zivot. 
This paper also provides a modification of the price discovery metric proposed by Yan and Zivot to make it less susceptible to extreme values and make it easily comparable to the well-established $I S$ and $C S$ metrics. The result is the 'information leadership share' (ILS). Importantly, we provide the first tests of the performance of this new metric. Given that our simulations highlight some very attractive features of $I L S$, particularly compared to existing metrics, we hope it will be used in future empirical work. Finally, we delve deeper into the implications for existing and future research, of both Yan and Zivot and the present paper's findings about what price discovery metrics really measure.

\section{What do researchers mean by "price discovery"?}

\subsection{The economic process of price discovery}

Part of the confusion and debate about alternative price discovery metrics stems from differences and lack of precision in definitions of price discovery. Here, we refer to definitions of the economic process rather than the empirical metrics, which we review in the next subsection. In order to correctly interpret the price discovery metrics it is essential to distinguish between speed and noise in the process of price discovery. Both are implicit in Lehman's (2002) definition of price discovery provided earlier, "efficient and timely incorporation of information ...". Timely refers to the relative speed with which a price series reflects new information about the fundamental value. Efficient implies a relative absence of noise, such as bid-ask bounce, tick discreteness, temporary deviations due to imperfect liquidity and so on.

In a multiple price series setting, by far the most widely accepted view of what it means for a price series to contribute to or to be dominant in price discovery stems from the seminal work of Hasbrouck (1995), which puts forward the "who moves first" view

of price discovery. Hasbrouck intended to measure "'who moves first' in the process of price adjustment" (p.1184) to innovations in the efficient price. Hasbrouck is very clear on what $I S$ does not measure; it does not measure the total amount of information impounded into prices, nor does it measure which market has the "best" prices. Hasbrouck illustrates the latter with an example of a market that is informationally dominant (and has an $I S$ of 100\%) because innovations in the market drive reactions in 
other markets, yet the informationally dominant market could also have the widest spreads and therefore not necessarily the "best" prices.

The vast majority of price discovery studies either: (i) follow Hasbrouck's "who moves first" view; or (ii) are not explicit in describing their view of price discovery, referring only to "share of price discovery", "contribution to price discovery", or "dominant in price discovery". For example, Booth et al. (1999) state that "price discovery is typically documented by noting the speed at which prices react to new information" (p.620). Chakravarty et al. (2004) interpret a price series as making a contribution to price discovery if it is the first to reflect at least some new information. Cabrera et al. (2009) state that "if the innovations in a market drive the reaction of the other markets, then this market is informationally dominant" (p.144). Rittler (2012) interprets a market as dominating price discovery if it incorporates information first. Mizrach and Neely (2008) use price discovery to mean "which of several markets tends to incorporate permanent changes in asset prices first" (p.1222). Forte and Pena (2009) consider the analysis of price discovery in related asset classes as a task of teasing out which asset class 'leads' the others.

A minority of studies describe price discovery in slightly broader terms, potentially admitting aspects other than simply leading the process of adjusting to new information, but unfortunately none are specific or precise about other aspects of relevance. For example, Harris et al. (2002) state that "price discovery is the process by which security markets attempt to identify permanent changes in equilibrium transaction prices" (p. 279). Chen and Gau (2010) assert, "the price discovery process refers to how price movements react to relevant information" (p.1628). Cao et al. (2009) interpret Hasbrouck information shares as indicators of a price series' informativeness "about the true value of the asset" (p.39).

In summary, a broad view sees a strong contribution to price discovery as involving efficient and timely incorporation of information about the fundamental value into the price. In a multiple price series setting the vast majority of the literature takes the view that a price series dominates price discovery if it is the first to adjust to new information about the fundamental value, and a price series makes a greater contribution to price discovery (is responsible for a larger "share" of price discovery) the more often it 
is the first to adjust to new information. This is different from measuring which price is the most informative about fundamental value because the price series that is the first to impound new information may also be considerably noisier than other price series potentially rendering it less useful as a measure of the fundamental value. The focus in the price discovery literature on which price series moves first rather than which is most informative follows from the objective of uncovering where and how information enters a market and gets impounded into prices. Knowing which price "moves first" regardless of how noisy it is contributes to achieving this objective; knowing which price is more informative does not necessarily.

\subsection{The empirical measures of price discovery}

Turning to the empirical measures of price discovery, both $I S$ and $C S$ rely on the notion that prices for the same asset (in different markets, for example) can deviate from one another in the short run due to trading frictions, but will converge in the long run because both are connected to the fundamental value of the asset. Such prices series are therefore cointegrated and lend themselves to empirical analysis using vector error correction models (VECM) under the assumption that the price series share a common random walk efficient price. Both $I S$ and $C S$ are derived from the estimates of a reduced form VECM. Hasbrouck (1995) proposes that the contribution of a price series to price discovery (the 'information share', $I S$ ) can be measured by the proportion of the variance in the common efficient price innovations that is explained by innovations in that price series. This approach follows naturally as an extension of Hasbrouck's earlier work (Hasbrouck, 1991) in which he proposes that the relative informativeness of trades could be measured by the proportion of efficient price variation attributable to trades. When price innovations across markets are correlated, the attribution of efficient price innovation variance cannot be done uniquely and instead one can estimate an upper and lower bound on a price series' $I S$.

The second commonly used metric, CS, is based on Gonzalo and Granger's (1995) work on the econometrics of cointegration, and is first applied to price discovery by Booth et al. (1999), Chu et al. (1999) and Harris et al. (2002). Gonzalo and Granger (1995) propose a method of decomposing a cointegrated price series into a permanent 
component and a temporary component using the error correction coefficients. In the context of price discovery the permanent component is interpreted as the common efficient price and the temporary component reflects deviations due to trading fractions. Importantly, Gonzalo and Granger (1995) show that the permanent component is a linear combination of all variables in the cointegration system (all the price series). Booth et al. (1999), Chu et al. (1999) and Harris et al. (2002) propose that a price series with greater weight in the linear combination moves more closely with the common efficient price and thus contributes more to price discovery. Therefore, under this approach a price series' contribution to price discovery (the 'component share', CS) is it's normalized weight in the linear combination of prices that forms the common efficient price. Baillie et al. (2002) show that although $I S$ and $C S$ seem dissimilar, they share a lot in common because both are closely related to the same combination of the reduced form error correction coefficients.

Lehmann (2002) points out that because $I S$ and $C S$ are both defined in terms of a reduced form VECM, their interpretation with respect to price discovery is not always clear because it is dependent on the (often unspecified) structural model of price formation. Yan and Zivot (2010) directly address this problem by specifying a fairly general structural cointegration model for asset prices and analytically demonstrating what $I S$ and $C S$ measure for that model. Their structural model, motivated by models used in empirical macroeconomics, consists of two price series that are driven by two sources of shocks: one permanent and one transitory. The permanent shocks represent innovations in the fundamental value and therefore, by definition, a one-unit permanent shock leads to a one-unit increase in each of the prices in the long run. The transitory shock represents noise due to trading frictions and therefore, by definition, a one-unit transitory shock has zero effect on the prices in the long run. The short-run impacts of the permanent and transitory shocks, however, are not restricted by the structural model; each price series is defined by two lag polynomials that describe its dynamic response to the permanent and transitory shocks. This allows the price series to differ in how quickly they reflect innovations in the fundamental value and how they are impacted by the transitory shocks. 
Within this setup, Yan and Zivot (2010) are able to express the $I S$ and $C S$ of a price series in terms of its dynamic response to permanent and transitory shocks (the lag polynomials). Their results indicate that $C S$ is a function of the dynamic responses of the two price series to the transitory shocks only, whereas $I S$ is a function of the dynamic responses of the two price series to the transitory and permanent shocks. This suggests that $I S$ and $C S$ can give misleading information regarding price discovery in some situations due to their dependence on the dynamic response to transitory shocks. A useful byproduct of this result is that $I S$ and $C S$ can be combined in an expression, $\left|\left(I S_{1} / I S_{2}\right)\left(C S_{2} / C S_{1}\right)\right|$, such that the dynamic responses to the transitory shocks cancel out, leaving only a ratio of the price series' dynamic responses to the permanent shocks. This metric can be useful in attributing price discovery because under certain assumptions it accurately measures the relative impact of permanent shocks on the two price series and, unlike $I S$ and $C S$, it is not influenced by how the price series respond to transitory shocks. The key assumptions underlying Yan and Zivot's (2010) results are: (i) there are only two price series; (ii) the structural model has only one permanent and one transitory shock; and (iii) the reduced form VECM errors are uncorrelated. For models of price formation that violate these assumptions it is not known to what extent the expression that combines $I S$ and $C S$ purges the responses to transitory shocks.

\section{Method}

We examine the relation between price discovery metrics and two key features of a price series: speed in impounding new information and noise. This choice is motivated by the fact that most price discovery research strives to identify which market impounds new information faster, yet Yan and Zivot (2010) find that $I S$ and CS also measure the relative avoidance of noise. For our main analysis we use a structural model of price formation that allows two price series to differ in: (i) the amount of noise; and (ii) the speed of adjustment to new information. Of the many models that could be used to achieve this, our choice is driven by three main considerations: (i) simplicity and intuitiveness; (ii) a clear separation of the speed and noise dimensions; and (iii) an independent source of trading frictions for each price series, consistent with many of the 
empirical settings that we describe later. In robustness tests we examine an alternative model.

The fundamental value of a stock is assumed to follow a random walk,

$$
m_{t}=m_{t-1}+u_{t}, \quad u_{t} \sim \mathrm{N}\left(0, \sigma_{u}\right),
$$

where $m_{t}$ is the natural $\log$ of the fundamental value at time $t$, and $u_{t}$ is i.i.d.. Price series $i$ tracks the fundamental value with a time delay of $\delta_{i}$ periods, and contains noise, $s_{i, t}$ :

$$
p_{i, t}=m_{t-\delta_{i}}+s_{i, t}, \quad s_{i, t} \sim \mathrm{N}\left(0, \sigma_{s_{i}}\right),
$$

where $p_{i, t}$ is the natural $\log$ of price series $i$ at time $t$, and $s_{i, t}$ is i.i.d. and uncorrelated across different price series (independent under normality). Therefore, the two parameters, $\delta_{i}$ and $\sigma_{s_{i}}$, characterize price series $i$ in terms of its speed of adjustment to innovations in the fundamental value (the speed with which it impounds new information) and its noise. Noise can arise for a number of reasons such as transaction prices "bouncing" between bid and ask quotes, a discrete price grid, a lack of liquidity resulting in temporary deviations from equilibrium prices, noise trading, and errors in converting from derivative prices to derivative-implied underlying asset prices. Although time could take any units, in what follows we treat time as being discrete and measured in 1-second intervals, consistent with much of the empirical literature.

The model of price formation given by equations (1) and (2), although simple and intuitive, does not satisfy the assumptions under which Yan and Zivot (2010) derive their results for what $I S$ and $C S$ measure. In particular, when the model is used to describe two price series, there are three shocks: one permanent and two temporary. This allows each price series to have an independent source of noise (trading frictions), which is a realistic feature of many price discovery applications including some of those described later in this section. In contrast, the structural cointegration model used by Yan and Zivot requires that there be only one permanent and one transitory shock. Therefore, it is not clear that Yan and Zivot's results will hold in our setting. Furthermore, the structural cointegration model implied by our design is not invertible and therefore we cannot perform the type of analytical exercise that is done in Yan and Zivot (2010). This necessitates our use of simulations to examine the various price discovery metrics. 
In the remainder of the paper we will consider the simple case of two price series. We treat price series $1, p_{1}$, as the reference price series by setting its parameters so that it has moderate speed and moderate noise. We then vary the parameters of price series 2 , $p_{2}$, to make it faster/slower and more/less noisy than $p_{1}$. In particular, we fix $p_{1}$ with the parameters $\delta_{1}=5$ (seconds) and $\sigma_{s_{1}}=5$ (b.p.) and we vary the parameters of $p_{2}$ through the following ranges that are centered on the 'moderate' values chosen for $p_{1}$ : $\delta_{2} \in\{0,1,2, \ldots, 10\}$ (seconds) and $\sigma_{s_{2}} \in\{0,1,2, \ldots, 10\}$ (b.p.). We set $\sigma_{u}=1$ (b.p.). We deliberately choose parameter values that approximately correspond to those of an average US stock in recent years, so that our simulations would reflect situations that could plausibly be encountered in empirical studies. ${ }^{3}$

Holding the parameters of $p_{1}$ fixed at moderate speed and moderate noise, the various speed and noise values for $p_{2}$ create an $11 \times 11$ grid of parameter combinations. This grid is illustrated in Figure 1. The vertical axis measures the delay in a price series' adjustment to innovations in the fundamental value. In regions below the dashed horizontal line at which both series have equal speed, i.e., in Quadrants 3 and $4, p_{2}$ is faster (less delay) than $p_{1}$. Therefore, according to the "who moves first" view of price discovery, $p_{2}$ would be considered the dominant price series in Quadrants 3 and 4 . The horizontal axis measures noise. In regions left of the dashed vertical line at which both series are equally noisy, i.e., in Quadrants 1 and $3, p_{2}$ is less noisy than price $p_{1}$. This could occur due to greater liquidity, a narrower spread, less noise trading, a finer tick resolution and so on. Therefore, in Quadrant 3, $p_{2}$ is superior in both elements: it is faster to adjust to innovations in the fundamental value and it is less noisy. Thus in Quadrant 3, $p_{2}$ is unambiguously superior in price discovery. In Quadrants 1 and $4, p_{2}$ has an advantage over $p_{1}$ in one element but not the other - either it is faster but noisier or it is less noisy but slower. In these regions it is debatable which price series has the "best" prices. Such judgment depends on how much value is placed on the speed with which

\footnotetext{
${ }^{3}$ We set: (i) the standard deviation of the noise parameter for the reference price series (5 b.p.) to be in the same order of magnitude as effective spreads (see, e.g., Hendershott et al., 2011); (ii) the volatility of the fundamental value ( 1 b.p./second) to be in the same order of magnitude as the average volatility of stocks, measuring volatility at a daily frequency then scaling to 1-second intervals so as to minimise the amount of high-frequency microstructure noise captured by the volatility estimates (see, e.g., Hendershott et al., 2011); and (iii) the delay of the reference price series (5 seconds) to be in the same order of magnitude as statistically significant midquote return autocorrelations (see, e.g., Hendershott and Jones, 2005).
} 
information is incorporated compared to avoidance of noise, as well as the relative strengths of the advantage/disadvantage in speed/noise. In Quadrant 2, $p_{2}$ is unambiguously a weaker contributor to price discovery; it is slower and noisier.

\section{$<$ Figure 1 here $>$}

The economic interpretation of the relations between $p_{1}$ and $p_{2}$ in each of the quadrants, by way of example, is as follows. In all quadrants we could consider the reference price series, $p_{1}$, as trade prices in a moderately liquid and efficient traditional stock exchange. In Quadrant $1, p_{2}$, which is slower to impound new information but less noisy, could for example be trade prices from a 'dark pool' (an off-exchange equities trading system that matches orders with no pre-trade transparency). Orders sent to a dark pool are often matched at the midpoint of the best bid and ask quotes prevailing on a traditional stock exchange, or sometimes at other prices within the spread. Therefore, trade prices from dark pools have less noise from microstructure frictions such as bid-ask bound and tick discreteness. Trades from dark pools are often printed to the public 'tape' of executed trades with a delay. For example, in the US, trades executed in dark pools are reported to the tape via trade reporting facilities, with a delay of up to 30 seconds.

In Quadrant 2, $p_{2}$, which is slower and noisier than $p_{1}$, could for example be trade prices from an alternative exchange that has a wider spread and tends to follow innovations on the primary exchange rather than contribute new information. To give another example, $p_{2}$ could be prices of trades that are comparatively more often liquidity motivated than information motivated, e.g., upstairs negotiated block trades compared to normal order book trades (Booth et al., 2002).

In Quadrant 3, $p_{2}$, which is both faster and less noisy, could be the quote midpoint of a market in comparison to the market's trade prices $\left(p_{1}\right)$. Such a comparison is studied by Cao et al. (2009). Midquotes are commonly used as a proxy for fundamental value because they contain less microstructure noise than trade prices, which are affected by bid-ask bounce. Furthermore, if informed traders use a relatively high proportion of limit orders because they face lower adverse selection risks (e.g., Rindi, 2008) then quotes may 
be faster to adjust to innovations in the fundamental value than trade prices (Goettler et al., 2009).

Finally, the situation in Quadrant 4, in which $p_{2}$ is faster to reflect innovations in fundamental value but is noisier than $p_{1}$, could arise in a hybrid market such as the NYSE where dealers can "cream skim" the uninformed order flow and offer it price improvement, leaving the relatively more informed order flow to trade in the limit order book (e.g., Bessembinder and Kaufman, 1997; Ready, 1999). In such circumstances, dealer trades $\left(p_{1}\right)$ might be less noisy due to price improvement that reduces the noise induced by the spread and at the same time have a larger delay in reflecting innovations in fundamental value compared to order book trades $\left(p_{2}\right)$ due to the lower prevalence of informed traders.

For each set of parameter values in the $11 \times 11$ grid we simulate 1,000 samples of 21,600 time-series observations, in total approximately 2.6 billion observations. The number 21,600 is chosen to imitate empirical studies, which often estimate the VECM for each stock-day using 1-second intervals, e.g., Hasbrouck (1995), Hasbrouck (2003), Hendershott and Jones (2005), Cao et al. (2009) (there are approximately 21,600 1second observations in a typical trading day in US stock markets). Figure 2 illustrates a sub-sample of the simulated price series and fundamental value for four sets of parameter values, corresponding to the four quadrants of Figure 1. It is visually apparent that different parameter combinations are able to capture various speed and noise characterizations that could exist in comparing two price series.

\section{$<$ Figure 2 here $>$}

For each set of parameter values and each of the 1,000 samples we estimate the following VECM:

$$
\begin{aligned}
& \Delta p_{1, t}=\alpha_{1}\left(p_{1, t-1}-p_{2, t-1}\right)+\sum_{i=1}^{20} \gamma_{i} \Delta p_{1, t-i}+\sum_{j=1}^{20} \delta_{j} \Delta p_{2, t-j}+\varepsilon_{1, t} \\
& \Delta p_{2, t}=\alpha_{2}\left(p_{1, t-1}-p_{2, t-1}\right)+\sum_{k=1}^{20} \phi_{k} \Delta p_{1, t-k}+\sum_{m=1}^{20} \varphi_{m} \Delta p_{2, t-m}+\varepsilon_{2, t}
\end{aligned}
$$


We calculate $I S_{1}, I S_{2}, C S_{1}$ and $C S_{2}$ from the error correction parameters and variancecovariance of the error terms, following Baillie et al. (2002). The component shares are obtained from the normalized orthogonal to the vector of error correction coefficients, $\alpha_{\perp}=\left(\gamma_{1}, \gamma_{2}\right)^{\prime}$, thus:

$$
C S_{1}=\gamma_{1}=\frac{\alpha_{2}}{\alpha_{2}-\alpha_{1}}, \quad C S_{2}=\gamma_{2}=\frac{\alpha_{1}}{\alpha_{1}-\alpha_{2}}
$$

Given the covariance matrix of the reduced form VECM error terms,

$$
\Omega=\left(\begin{array}{cc}
\sigma_{1}^{2} & \rho \sigma_{1} \sigma_{2} \\
\rho \sigma_{1} \sigma_{2} & \sigma_{2}^{2}
\end{array}\right)
$$

and its Cholesky factorization, $\Omega=M M^{\prime}$, where

$$
M=\left(\begin{array}{cc}
m_{11} & 0 \\
m_{12} & m_{22}
\end{array}\right)=\left(\begin{array}{cc}
\sigma_{1} & 0 \\
\rho \sigma_{2} & \sigma_{2}\left(1-\rho^{2}\right)^{1 / 2}
\end{array}\right),
$$

the $I S$ are calculated using:

$$
I S_{1}=\frac{\left(\gamma_{1} m_{11}+\gamma_{2} m_{12}\right)^{2}}{\left(\gamma_{1} m_{11}+\gamma_{2} m_{12}\right)^{2}+\left(\gamma_{2} m_{22}\right)^{2}}, \quad I S_{2}=\frac{\left(\gamma_{2} m_{22}\right)^{2}}{\left(\gamma_{1} m_{11}+\gamma_{2} m_{12}\right)^{2}+\left(\gamma_{2} m_{22}\right)^{2}} .
$$

Because the estimates of $I S$ are affected by the ordering of the price series in the VECM, we use the approach advocated by Baillie et al. (2002) (also used by Booth et al. (2002), Cao et al. (2009), Chen and Gau (2010), Korczak and Phylaktis (2010) and others) and calculate $I S$ under each of the two possible orderings and then take the simple average.

We calculate the Yan-Zivot information leadership metric using:

$$
I L_{1}=\left|\frac{I S_{1}}{I S_{2}} \frac{C S_{2}}{C S_{1}}\right|, \quad I L_{2}=\left|\frac{I S_{2}}{I S_{1}} \frac{C S_{1}}{C S_{2}}\right| .
$$

We introduce the terminology "information leadership" to refer to this metric because it comes from an (unnamed) expression derived by Yan and Zivot (2010) to measure which price series leads the process of adjusting to innovations in the fundamental value. As described earlier, in Yan and Zivot's structural cointegration model CS measures the level of noise in one price series relative to the other, and $I S$ measures a combination of relative level of noise and relative leadership in reflecting innovations in the fundamental value. Recognizing this, Yan and Zivot proposed combining $C S$ and $I S$ as in equation (8) 
so that the relative level of noise would cancel out and leave a clean measure of relative informational leadership.

Unlike $I S$ and $C S$, the $I L$ proposed by Yan and Zivot is not a "share" in that $I L_{1}$ and $I L_{2}$ do not sum to 1 (or even approximately 1 ). Rather, $I L_{1}$ has the range $[0, \infty$ ). Values of $I L_{1}$ above (below) 1 suggest that $p_{1}$ leads (does not lead) the process of incorporating new information about the fundamental value. In order to make the information leadership metric easier to interpret and more readily comparable to $I S$ and $C S$ we define the "information leadership shares" (ILS) of $p_{1}$ and $p_{2}$ as:

$$
I L S_{1}=\frac{I L_{1}}{I L_{1}+I L_{2}}, \quad I L S_{2}=\frac{I L_{2}}{I L_{1}+I L_{2}} .
$$

Now, $I L S_{1}$ and $I L S_{2}$ have the range [0,1], similar to $I S$ and $C S$, with values above (below) 0.5 indicating the price series leads (does not lead) the process of adjusting to innovations in the fundamental value. In addition to being more readily comparable to IS and CS, ILS has the added advantage of not producing extreme values which occur in $I L$ when both $I S$ and $C S$ approach the value 1.

\section{Results}

\subsection{Main results}

Tables 1-3 report means and standard deviations of each of the three price discovery metrics (IS, CS and $I L S$ ) across the 1,000 samples of simulated data. The distribution of price discovery metric estimates in the 1,000 samples approximates the sampling distribution of the metrics and therefore the reported mean and standard deviation are Monte Carlo estimates of the sampling distribution's mean and the estimator's standard error. ${ }^{4}$ The Tables have the same layout as Figure 1: rows correspond to different values of the delay in $p_{2}, \delta_{2}$, and columns correspond to different values of the noise in $p_{2}, \sigma_{s_{2}}$. Bold is used to indicate rows/columns in which the delay/noise of $p_{2}$ is equal to that of $p_{1}$ and therefore divide the tables into four quadrants as in Figure 1. Grey shading is used to indicate parameterizations for which the mean of

\footnotetext{
${ }^{4}$ The standard error of the reported estimate of the sampling distribution's mean is the standard deviation reported in the Tables divided by $\sqrt{1000}$.
} 
the price discovery metric is greater than 0.5 . In other words, grey shading marks regions in which the price discovery metric suggests that $p_{2}$ is dominant in price discovery. ${ }^{5}$

The results indicate that only $I L S$ reliably measures price discovery in a "who moves first" sense. The shaded areas of Table 3, i.e., regions in which the ILS metric suggests $p_{2}$ is dominant in price discovery, correspond exactly to Quadrants 3 and 4 (ignoring the row in which both price series have equal delay). In these quadrants the structural parameters are such that $p_{2}$ adjusts to innovations in the fundamental value faster than $p_{1}$. The ILS metric is relatively unaffected by differences in the noise of $p_{1}$ and $p_{2}$; it focuses squarely on differences in informational leadership.

The $I S$ and $C S$ metrics on the other hand, have shaded regions that cut diagonally across the parameter space with different slopes, suggesting that they measure, to varying extents, both informational leadership and relative avoidance of noise. To illustrate, consider the row where $\delta_{2}=7$, i.e., $p_{2}$ reflects innovations in the fundamental with a slightly larger delay ( 7 seconds) than $p_{1}$ (5 seconds). When the noise parameter of $p_{2}$ takes the value $\sigma_{S_{2}}=1$ both $I S$ and $C S$ suggest that $p_{2}$ is dominant in price discovery, despite the fact that $p_{2}$ takes longer to adjust to innovations in the fundamental value (the estimates of $I S_{2}$ and $C S_{2}$ are 0.70 and 0.85 , respectively). This occurs because for the given parameter values, $p_{2}$ contains less noise than $p_{1}$ and in this case $p_{2}$ 's relative avoidance of noise outweighs its more sluggish reaction to innovations in the fundamental value. Furthermore, holding the delay in $p_{2}$ constant (staying on the row where $\delta_{2}=7$ ) and examining a different value of noise in $p_{2}$, say $\sigma_{s_{2}}=5$, both $I S$ and $C S$ now suggest that for these parameters $p_{1}\left(\right.$ not $\left.p_{2}\right)$ is dominant in price discovery. The estimate of $I S_{2}$ falls from 0.70 to 0.27 and $C S_{2}$ from 0.85 to 0.37 , despite the fact that the relative speed at which $p_{1}$ and $p_{2}$ incorporate new information has not changed.

In short, the amount of noise in a price series affects the $I S$ and $C S$ metrics independently of the speed at which the series reflect innovations in the fundamental value. The influence of noise on the $I S$ and $C S$ metrics can outweigh the extent to which they measure informational leadership and therefore these measures can in some

\footnotetext{
${ }^{5}$ In shading cells we do not include a margin for sampling error because in this setting there is no reason to treat the dominance of one price series as the null hypothesis and the other as the alternative.
} 
circumstances attribute price discovery dominance to markets or order flow types that are slower to reflect innovations in the fundamental value, i.e., IS and $C S$ do not always correspond to the "who moves first" view of price discovery.

Comparing $I S$ and $C S$, the flatter slope of the interface between the shaded and non-shaded regions for $I S$ indicates that $I S$ places more emphasis on "who moves first", relative to avoidance of noise, compared to CS. This is consistent with the analytical results of Yan and Zivot (2010) who show that CS is closely related to the relative avoidance of noise, while $I S$ measures both relative avoidance of noise and informational leadership. One difference from Yan and Zivot's analytic results, however, is that in our simulations CS measures to some extent the relative speed at which a price series impounds new information, not just the relative avoidance of noise.

Viewing price discovery from the "who moves first" perspective, there are two regions in which $I S$ and $C S$ incorrectly attribute price discovery dominance: shaded cells in Quadrant 1 (and the interface of Quadrants 1 and 3) and non-shaded cells in Quadrant 4. These errors bear resemblance to Type I and Type II statistical errors. In the former case $I S$ and $C S$ assign price discovery dominance to a more sluggish price series as a result of it being relatively less noisy and in the latter case $I S$ and $C S$ fail to assign price discovery dominance to a price series that is the first to adjust to innovations in the fundamental value, simply because the price series is relatively more noisy. In a total of 43 cells $C S$ incorrectly attributes price discovery dominance under the "who moves first" view, compared to 24 cells using the $I S$ metric, again illustrating that $I S$ more closely corresponds to the "who moves first" view of price discovery than does CS. Note, for comparison that $I L S$ makes zero errors in attribution of price discovery dominance under this view of price discovery.

In addition to comparability with $C S$ and $I S$, another advantage of constructing $I L S$ as a share that ranges from 0 to 1 is that it does not produce extreme outlier values, unlike $I L$. Appendix A provides the mean and standard deviation of $I L$ in our simulation. Using the mean values, the attribution of price discovery dominance is essentially the same as for $I L S$, consistent with the fact that the transformation from $I L$ to $I L S$ is monotonic and does not alter whether a point estimate suggests a price series is dominant in price discovery. What is different compared to ILS is that the Monte Carlo standard 
deviations for some parameterizations of the structural model become very large relative to the mean, due to extreme values in $I L$. For example, when price series 2 is much faster and much less noisy than price series 1 (the bottom left-hand corner of the grid of parameter values) the standard deviation of $I L$ (79.65) is approximately four times greater than its mean (19.51) whereas for $I L S$ Table 3 indicates that the standard deviation (0.07) is considerably smaller than the mean (0.97).

\subsection{Robustness tests}

We also examine the price discovery metrics using an alternative structural model in which markets partially adjust to innovations in the fundamental value. As before, the fundamental value of a stock is assumed to follow a random walk,

$$
m_{t}=m_{t-1}+u_{t}, \quad u_{t} \sim \mathrm{N}\left(0, \sigma_{u}\right),
$$

where $m_{t}$ is the natural $\log$ of the fundamental value at time $t$, and $u_{t}$ is i.i.d.. Price series $i$ responds partially to a contemporaneous innovation in the fundamental value (with partial response parameter $\lambda_{i}$ ) and contains noise, $s_{i, t}$ :

$$
p_{i, t}=m_{t-1}+\lambda_{i} u_{t}+s_{i, t}, \quad s_{i, t} \sim \mathrm{N}\left(0, \sigma_{s_{i}}\right),
$$

where $p_{i, t}$ is the natural $\log$ of price series $i$ at time $t$, and $s_{i, t}$ is i.i.d. and uncorrelated across different price series.

In this alternative model the degree of adjustment to contemporaneous innovations in the fundamental value, $\lambda_{i} \in[0,1]$, reflects the speed at which a price series reflects new information. With complete adjustment $\left(\lambda_{i}=1\right)$ the price series reflects new information instantaneously, and with the weakest adjustment $\left(\lambda_{i}=0\right)$ the price series only reflects new information with a delay of one period. Therefore, the alternative model does not allow as much variation in speed of incorporating new information compared to our main model, and consequently we place more emphasis on the results from the main model.

In analyzing $I S, C S$ and $I L S$ using the alternative model, we follow the same procedure as with the main model. We fix $p_{1}$ with the parameters $\lambda_{1}=0.5$ and $\sigma_{s_{1}}=5$ (b.p.) and we vary the parameters of $p_{2}$ through the following ranges that are centered on 
the 'moderate' values chosen for $p_{1}: \lambda_{2} \in\{0.0,0.1,0.2, \ldots, 1.0\}$ and $\sigma_{s_{2}} \in\{0,1,2, \ldots, 10\}$ (b.p.).

The results show a similar pattern as before: ILS is more closely related to speed of adjustment to innovations in the fundamental value, whereas $I S$ and $C S$ measure a combination of speed and relative avoidance of noise. ${ }^{6}$ Because the alternative model allows less variation in the speed of adjustment to new information the results are more heavily influenced by differences in noise levels. In particular, the price series to which $I S$ and $C S$ attribute dominance in price discovery is almost entirely driven by which price series has the lower level of noise, and even ILS is to some extent influenced by differences in noise levels, although to a much lesser extent than IS and CS. Importantly, our main conclusions are robust to this alternative structural model.

\section{Discussion and implications for existing and future price discovery studies}

Our results suggest that if one views price discovery under the common "who moves first" view, different levels of noise in the price series being compared cause bias in $I S$ and $C S$ as measures of relative contribution to price discovery. The influence of noise on $I S$ and $C S$ is only a bias if the view of price discovery is "who moves first". Under other views of price discovery involving combinations of leading the process of impounding new information and relative avoidance of noise $I S$ and $C S$ might be considered unbiased measures. An example of when this might be the case is if the objective was to identify the most informative price.

For the structural models of price formation used in our simulations (and the structural cointegration model used by Yan and Zivot (2010)) IS is an unbiased measure of a price series' contribution to impounding new information if an additional condition is satisfied: the prices series being compared have an equal level of noise. In our simulations this is equivalent to considering only the central bold-faced column in which the noise levels in $p_{1}$ and $p_{2}$ are equal. For this column all three metrics correctly identify the price series that is the first to reflect innovations in the fundamental value.

The requirement of equal noise to reconcile the use of $I S$ and $C S$ with the "who moves first" view implies that studies using price series that substantially differ in their

\footnotetext{
${ }^{6}$ These results are not tabulated for conciseness but are available upon request.
} 
level of noise will suffer from a much larger disconnect between what they intend to measure and what they actually measure, compared to studies that analyze price series of a similar noise level. For example, the disconnect is likely to be relatively small in studies that compare the contributions to price discovery of different stock exchanges or trading venues that have similar structure using cross-listed stocks (e.g., Hasbrouck, 1995; Huang, 2002; Harris et al., 2002; Eun and Sabherwal, 2003; Pascual et al., 2006; Frijns et al., 2010; Korczak and Phylaktis, 2010; Chen and Sub Choi, 2012; Chen et al., 2013). This is particularly true when the studies are able to use bid-ask midpoints (or bid or ask quotes) from the alternative markets rather than trade prices and thereby avoid the potential difference in noise that could be induced by different size spreads. Equal noise levels are also more likely when tick sizes across the markets are the same, when the mix of trader types (e.g., hedgers, speculators, institutional, retail) is similar, and when the liquidity of the alternative markets is similar.

On the other hand, the disconnect between what researchers intend to measure and what the metrics used actually measure is likely to be relatively large in studies that compare entirely different types of markets, different asset classes, or different types of prices. Examples include studies that analyze the price discovery contributions of stock options compared to stocks (e.g., Chakravarty et al., 2004) futures compared to spot markets (e.g., Booth et al., 1999; Chu et al., 1999; Covrig et al., 2004; Shastri et al., 2008; Mizrach and Neely, 2008; Cabrera et al., 2009; Chen and Gau, 2010; Liu and An, 2011; and Rittler, 2012), options compared to futures (e.g., Booth et al., 1999; Hsieh et al., 2008; and Chen and Chung, 2012), CDS compared to bonds and stocks (e.g., Forte and Pena, 2009), screen-based compared to open-outcry (floor) trading (e.g., Ates and Wang, 2005), different contract maturities (e.g., Fricke and Menkhoff, 2011), quotes compared to trade prices (e.g., Cao et al., 2009) and order flow from different types of traders (e.g., Fong and Zurbruegg, 2003; Kurov and Lasser, 2004; Anand and Subrahmanyam, 2008; and Anand et al., 2011). In what follows we briefly discuss a few examples of the types of studies listed above and show how the insights from our simulations give rise to a somewhat different view of the results in some existing studies.

Generally, the different types of market or different asset classes studied by the papers listed above differ in bid-ask spreads, liquidity, and design features such as tick 
size, contract specifications, and trading mechanism. All of these liquidity and microstructure differences cause the analyzed price series to have different levels of noise. This induces bias in the $I S$ and $C S$ metrics and can lead to misleading indications of which market or asset class is dominant in price discovery. The problem is amplified by the use of transaction prices rather than midquotes and many studies of asset classes other than stocks are constrained to using transaction prices.

Furthermore, the need to convert prices of different contracts or asset classes so that they would be comparable also creates noise that differs across the price series. For example, in Chakravarty et al. (2004), option prices are inverted to arrive at implied stock prices using lagged implied volatility, assuming that volatility remains constant over the lag period. This process introduces noise in the option-implied stock price, which, all else equal, causes downward bias in the option market $I S$ and results in understating the contribution of the options market to price discovery. This helps explain why Chakravarty et al. (2004) document that the option market $I S$ is only $17 \%$ on average despite the theoretical reasons to believe the options market would be the venue favored by informed traders. In Mizrach and Neely (2008) the series of adjustments required to relate a Treasury note futures price to the spot price include conversion factors for the futures contracts, accrued interest over different length periods for both futures and spot prices, the discount rate, and splicing of different maturity futures contracts. These adjustments inevitably create more noise in one or the other asset class, causing $I S$ and $C S$ to provide misleading indications of the contributions to price discovery, given that the authors use price discovery to mean "which of several markets tends to incorporate permanent changes in asset prices first" (p.1222).

In fact, several studies obtain results that are consistent with our finding that noise influences $I S$ and $C S$ independent of the speed at which the price series adjust to innovations in the fundamental value. For example, regression estimates in Mizrach and Neely (2008) indicate that an increase in the relative spread of the spot market (increase in spot price noise) decreases the spot market $I S$ and $C S$ (estimated using transaction prices), as would be predicted by our results. Chakravarty et al. (2004) find that option market $I S$ tends to be higher when option spreads are narrow and stock spreads are wide. Ates and Wang (2005) find that as spreads in electronic trading decline relative to the 
floor trading spreads (i.e., a relative decrease in noise in the electronic trading prices) the $I S$ of electronic trading transaction prices increases. However, none of these studies attempt to use the relations between microstructure variables and $I S / C S$ to control for the bias in the price discovery metrics and try to get a clearer picture of which asset class leads in price discovery.

We use four recent studies to illustrate that the use of $I S$ and $C S$ without proper regard for the impact of different noise levels on these metrics can lead to substantially misleading conclusions. Table 4 reports $I S, C S$, and $I L S$ estimates for the studies by Mizrach and Neely (2008), Rittler (2012), Hsieh et al. (2008) and Chen and Gau (2010). The $I S$ and $C S$ estimates are transposed directly from the original papers, whereas $I L S$ is obtained from our calculations using equations (8) and (9). For each study we report $I S$, $C S$, and $I L S$ for only one of the two price series because the estimates for the second price series are simply one minus the estimate for the first price series. All four studies aim to identify which market is the first to reflect new information. Given the differences in noise inherent in the compared price series, only $I L S$ will reliably identify the market that reacts first to new information.

$<$ Table 4 here $>$

Mizrach and Neely (2008) analyze price discovery in the US Treasuries, comparing the contributions of the futures and spot markets. They conclude that the Treasury futures market plays an important role in price discovery compared to the spot market because in the 5-year and 10-year notes the futures market typically (in all but two note-years) has an $I S$ in excess of 50\% (the average of the futures contract $I S$ for the 5 -year and 10-years notes is $51 \%$ and $68 \%$, respectively). However, ILS tells a completely different story; the futures share of price discovery is below $50 \%$ for all noteyears, with an average of only $15 \%$ for the 5 -year note and $26 \%$ for the 10 -year note. This illustrates the severity of the bias in $I S$ and $C S$ induced by differences in the relative levels of noise in the two price series.

Rittler (2012) analyzes price discovery in the European Union emissions trading scheme, comparing the contributions of the spot and futures markets. He concludes that: 
(i) the futures market is the "leader" of the price discovery process, it "incorporates information first and then transfers the information to the spot market"; and (ii) the informational leadership of the futures market becomes stronger through time. These conclusions are based on the fact that the $I S$ and $C S$ estimates for the futures market for the full sample are in the order of $70 \%$ and that they increase from 2008 to 2009. However, the ILS estimates reveal that in fact the exact opposite is true: the futures market's share of price discovery in an information leadership sense is only $31 \%$ in the full sample (taking the average of the two sampling frequencies) and declines substantially from 2008 to 2009. Again, the choice and interpretation of the price discovery metric has an immense impact on the conclusions that can be drawn.

Hsieh et al. (2008) compare the contributions to price discovery made by index futures and index options. They assert that index futures dominate the price discovery process compared to index options because the $I S$ and $C S$ estimates for the futures market using the put-call-parity (PCP) method of imputing spot prices are $66 \%$ and $83 \%$, respectively. However, ILS again leads to vastly different conclusions; the share of price discovery attributable to the futures market is only 14\% using the PCP method and 5\% using the Black-Scholes method, suggesting that the index options rather than the futures dominate price discovery.

Finally, Chen and Gau (2010) compare price discovery in the spot and futures markets for the currency pairs JPY-USD and EUR-USD. They conclude that the spot market provides more price discovery than does the future market because the spot market $I S$ and $C S$ are in the range of $63 \%$ to $72 \%$. However, $I L S$ reveals the opposite is true: the spot market's contribution to price discovery is only $38 \%$ and $36 \%$ for the two currency pairs in the full sample. Furthermore, Chen and Gau (2010) conclude that the price discovery role of the spot market increases through the course of a trading day because the $I S$ and $C S$ estimates increase monotonically through intraday intervals. Again, ILS reveals this is not the case: for JPY-USD the spot market's contribution to price discovery goes from $49 \%$ at the start of the day through to $43 \%$ at the end of the day (non-monotonically) and for EUR-USD from 53\% at the start of the day through to $54 \%$ at the end of the day (non-monotonically). A possible explanation for the fact that $I S$ and $C S$ increase monotonically through the day but $I L S$ does not is that $I S$ and $C S$ are 
picking up an intraday pattern in spreads, whereas $I L S$ is not as heavily influenced by such microstructure frictions. Therefore, $I L S$ can provide a better indication of how informational leadership changes at intraday horizons.

The four recent price discovery studies chosen for illustrative purposes demonstrate that the choice and interpretation of the price discovery metric can have profound effects on the conclusions about price discovery. In fact, it can change conclusions to polar opposites. There are many other studies such as the four discussed here for which conclusions could be reexamined by computing $I L S$ from reported $I S$ and $C S$ estimates. Unfortunately, however, there are also many existing studies that report only $I S$ or $C S$ estimates, prohibiting a simple reassessment of the findings.

The discussion and examples in this section have the following implications for future research. First, it is important to choose the most appropriate price discovery metric for the application and interpret the estimates with regard for what the metric actually measures in terms of speed of adjustment to new information and relative avoidance of noise. In applications where there are likely to be different levels of noise in the price series of interest and the researcher's intent is to measure the "who moves first" or informational leadership aspect of price discovery then our simulation results suggest $I L S$ is the most suitable metric. Second, as the examples in this section illustrate there are many areas of price discovery research that are worth revisiting with greater awareness of what price discovery metrics actually measure. This is particularly the case for applications in which the effects of different levels of noise are likely to be most severe, such as comparisons of different asset classes, types of market, sources of order flow and types of prices. Third, the common practice of estimating both $I S$ and $C S$ for 'robustness' does not overcome the potential problems in these metrics because both, to varying extents, measure the relative avoidance of noise and thus can obscure identification of informational leadership when differences in noise levels are substantial. It is however, still advisable to estimate both metrics, but for a different reason: the two metrics interpreted together allow one to disentangle informational leadership from relative avoidance of noise. One way to do this is to calculate $I L S$ from the $I S$ and CS estimates. 


\section{Conclusions}

In comparing the contributions of two or more price series (markets, order flow sources, price types) to price discovery researchers often seek to identify which market is, relatively speaking, the leader in reflecting innovations in the fundamental value, i.e., which price series is faster in impounding new information. The simulations reported in this paper indicate that the two workhorses of the price discovery literature - Hasbrouck information share (IS) and Harris-McInish-Wood component share $(C S)$ - provide an accurate measure of this aspect of price discovery only in limited circumstances: when the price series being compared have similar levels of noise. In general, price series can differ in the levels of noise for a number of reasons including: different bid-ask spreads; various microstructure frictions such as tick size, trading mechanism and contract specifications; conversions required to make prices from different asset classes comparable; different levels of liquidity; and noise trading that causes temporary deviations from equilibrium prices.

Our simulations illustrate that when the price series differ in the levels of noise, $I S$ and $C S$ both measure a combination of leadership (relative speed) in impounding new information and relative avoidance of noise, to different extents. Of the two workhorse metrics, IS places more emphasis on informational leadership than avoidance of noise compared to $C S$ and is therefore more closely related to the aspect of price discovery that researchers often seek to measure. A third price discovery metric, stemming from Yan and Zivot (2010) and modified in this paper to be comparable to $I S$ and $C S$ and therefore termed the 'informational leadership share' (ILS), overcomes the susceptibility to different levels of noise. It does this by combining the $I S$ and $C S$ metrics in such a way that their dependence on the level of noise cancels out, and thus it provides a more robust measure of the contribution of a price series to impounding new information. In summary, $C S$ values low noise relative to speed, $I S$ values speed relative to low noise, and $I L S$ values only speed.

Our results have some important limitations. First, we construct ILS based on the analytic results of Yan and Zivot (2010), which rely on three key assumptions: (i) there are only two price series; (ii) the structural model has only one permanent and one transitory shock; and (iii) the reduced form VECM errors are uncorrelated. Under these 
assumptions ILS measures informational leadership and is not affected by the relative level of noise in a price series. However, it is not clear how reliably ILS measures informational leadership when these assumptions are violated. Our simulations test $I L S$ in settings, in which one of the assumptions is violated (our structural models have one permanent and two transitory shocks) and ILS continues to perform well in attributing informational leadership, but we cannot say whether this is also true of other settings. Second, our Monte Carlo simulations necessarily use stylized models of price formation. We argue that these models capture key features of actual prices and provide a series of examples to illustrate how our models map to real situations. However, as with all stylized models, we cannot know if the underlying structure and parameterization is a sufficiently close representation of the true price formation processes encountered in empirical studies.

Examining the three price discovery metrics in a handful of recent empirical studies we find that the choice and interpretation of the price discovery metric can have a substantial impact on the conclusions of price discovery studies. In four examples of recent studies, our computation of ILS based on the $I S$ and $C S$ estimates reported in the papers leads to substantially different, in most cases opposite, conclusions to those made by the studies. For example, Rittler (2012) concludes that futures dominate price discovery in the EU emission trading market and that their dominance has increased through time, whereas $I L S$ indicates the opposite: the spot market leads price discovery overall, and the contribution of the futures market to price discovery has declined through time. Similarly, Hsieh et al. (2008) conclude that futures dominate options in price discovery for the Taiwan stock index, whereas $I L S$ suggests that the opposite is true. The choice of price discovery metric and correct interpretation of what the metric actually measures in the particular setting are crucial to drawing correct conclusions about where/how price discovery occurs.

Our results have implications for existing studies that use $I S$ and/or $C S$ metrics. Settings in which the levels of noise are likely to be similar across the various price channels (e.g., a stock trading in multiple venues of similar structure and liquidity) are likely to have more robust conclusions about the nature of price discovery than settings in which there are substantial differences in noise. When noise levels differ significantly 
across price channels, e.g., different asset classes, different market structures, different types of traders, and comparisons of quotes with transaction prices, then existing conclusions should be interpreted keeping in mind the effects of noise on the price discovery metrics. In particular, $I S$ and even more so $C S$, are likely to overstate the contribution to price discovery of the less noisy price series. Where possible, computing $I L S$ from reported $I S$ and $C S$ estimates as in our examples can be a useful way of getting new insights from existing studies.

For future research it goes without saying that the choice and interpretation of the price discovery metric is critically important. In analyzing two price series for which the noise levels may differ if the intent is to measure the relative speed at which they impound new information then $I L S$ is likely to be a suitable metric. Furthermore, the illustrations of how substantially conclusions can change depending on the choice of metric suggest a number of previously studied settings that may be worth revisiting, including the role of different asset classes, market structures, types of traders, and types of prices. 


\section{References}

Anand, A., V.A. Gatchev, L. Madureira, C.A. Pirinsky, and S. Underwood, 2011, Geometric proximity and price discovery: Evidence from NASDAQ, Journal of Financial Markets 14, 193-226.

Anand, A., and A. Subrahmanyam, 2008, Information and the intermediary: Are market intermediaries informed traders in electronic markets?, Journal of Financial and Quantitative Analysis 43, 1-28.

Ates, A., and G.H.K. Wang, 2005, Information transmission in electronic versus openoutcry trading systems: An analysis of US euity index futures markets, Journal of Futures Markets 25, 679-715.

Baillie, R.T., G.G. Booth, G., Y. Tse, and T. Zabotina, 2002, Price discovery and common factor models, Journal of Financial Markets 5, 309-321.

Bessembinder, H., and H.M. Kaufman, 1997, A Cross-exchange comparison of execution costs and information flow for NYSE-listed stocks, Journal of Financial Economics 46, 293-319.

Booth, G.G., R.W. So, and Y. Tse, 1999, Price discovery in the German equity index derivatives markets, Journal of Futures Markets 19, 619-643.

Booth, G.G., J. Lin, T. Martikainen, and Y. Tse, 2002, Trading and pricing in upstairs and downstairs stock markets, Review of Financial Studies 15, 1111-1135.

Cabrera, J., T. Wang, and J. Yang, 2009, Do futures lead price discovery in electronic foreign exchange markets?, Journal of Futures Markets 29, 137-156.

Cao, C., O., Hansch, and X. Wang, 2009, The information content of an open limit-order book, Journal of Futures Markets 29, 16-41.

Chakravarty, S., H. Gulen, and S. Mayhew, 2004, Informed trading in stock and option markets, Journal of Finance 59, 1235-1257.

Chen, W.-P., and H. Chung, 2012, Has the introduction of S\&P 500 ETF options led to improvements in price discovery in SPDRs?, Journal of Futures Markets 32, 683711.

Chen, Y.-L., and Y.-F. Gau, 2010, News announcements and price discovery in foreign exchange spot and futures markets, Journal of Banking and Finance 34, 1628-1636.

Chen, H., and P.M. Sub Choi, 2012, Does information vault Niagara Falls? Cross-listed 
trading in New York and Toronto, Journal of Empirical Finance 19, 175-199.

Chen, H., P.M. Sub Choi, and Y. Hong, 2013, How smooth is price discovery? Evidence from cross-listed stock trading, Journal of International Money and Finance 32, 668-699.

Chu, Q.C., W.G. Hsieh, and Y. Tse, 1999, Price discovery on the S\&P 500 index markets: An analysis of spot index, index futures and SPDRs, International Review of Financial Analysis 8, 21-34.

Covrig, V., D.K. Ding, and B.S. Low, 2004, The contribution of a satellite market to price discovery: Evidence from the Singapore Exchange, Journal of Futures Markets 24, 981-1004.

Eun, C.S., and S. Sabherwal, 2003, Cross-border listings and price discovery: Evidence from US-listed Canadian stocks, Journal of Finance 58, 549-575.

Forte, S., and J.I. Pena, 2009, Credit spreads: An empirical analysis of the informational content of stocks, bonds, and CDS, Journal of Banking and Finance 33, 2013-2025.

Fong, K., and R. Zurbruegg, 2003, How much do locals contribute to the price discovery process? Journal of Empirical Finance 10, 305-320.

Fricke, C., and L. Menkhoff, 2011, Does the "Bund" dominate price discovery in Euro bond futures? Examining information shares, Journal of Banking and Finance 35, 1057-1072.

Frijns, B., A. Gilbert, and A. Tourani-Rad, 2010, The dynamics of price discovery for cross-listed shares: Evidence from Australia and New Zealand, Journal of Banking and Finance 34, 498-508.

Goettler, R.L., C.A. Parlour, and U. Rajan, 2009, Informed traders and limit order markets, Journal of Financial Economics 93, 67-87.

Gonzalo, J., and C. Granger, 1995, Estimation of common long-memory components in cointegrated systems, Journal of Business and Economic Statistics 13, 27-35.

Harris, F.H.deB., T.H. McInish, and R.A. Wood, 2002, Security price adjustment across exchanges: An investigation of common factor components in Dow stocks, Journal of Financial Markets 5, 277-308.

Hasbrouck, J., 1995, One security, many markets: Determining the contributions to price discovery, Journal of Finance 50, 1175-1199. 
Hasbrouck, J., 2003, Intraday price formation in US equity index markets, Journal of Finance 58, 2375-2400.

Hasbrouck, J., 1991, The summary informativeness of stock trades: An econometric analysis, Review of Financial Studies 4, 571-595.

Hendershott, T., and C.M. Jones, 2005, Island goes dark: Transparency, fragmentation, and regulation, Review of Financial Studies 18, 743-793.

Hendershott, T., C.M. Jones, and A.J. Menkveld, 2011, Does algorithmic trading improve liquidity?, Journal of Finance 66, 1-33.

Hsieh, W.-L.G., C.-S. Lee, and S-F. Yuan, 2008, Price discovery in the options market: An application of put-call parity, Journal of Futures Markets 28, 354-375.

Huang, 2002, The quality of ECN and Nasdaq market maker quotes, Journal of Finance $57,1285-1319$.

Korczak, P., and K. Phylaktis, 2010, Related securities and price discovery: Evidence from NYSE-listed non-US stocks, Journal of Empirical Finance 17, 566-584.

Kurov, A., and D.J. Lasser, 2004, Price dynamics in the regular and E-Mini futures markets, Journal of Financial and Quantitative Analysis 39, 365-384.

Lehmann, B.N., 2002, Some desiderata for the measurement of price discovery across markets, Journal of Financial Markets 5, 259-276.

Liu, Q., and Y. An, 2011, Information transmission in informationally linked markets: Evidence from US and Chinese commodity futures markets, Journal of International Money and Finance 30, 778-795.

Mizrach, B., and C.J. Neely, 2008, Information shares in the US Treasury market, Journal of Banking and Finance 32, 1221-1233.

Pascual, R., B. Pascual-Fuster, and F. Climent, 2006, Cross-listing, price discovery and the informativeness of the trading process, Journal of Financial Markets 9, 144161.

Ready, M., 1999, The specialist's discretion: Stopped orders and price improvement, Review of Financial Studies 16, 301-343.

Rindi, B., 2008, Informed traders as liquidity providers: Anonymity, liquidity and price formation, Review of Finance 12, 1075-1112. 
Rittler, D., 2012, Price discovery and volatility spillovers in European Union emissions trading scheme: A high-frequency analysis, Journal of Banking and Finance 36, 774-785.

Shastri, K., R.S. Thirumalai, and C.J. Zutter, 2008, Information revelation in the futures market: Evidence from single stock futures, Journal of Futures Markets 28, 335353.

Yan, B., and E. Zivot, 2010, A structural analysis of price discovery measures, Journal of Financial Markets 13, 1-19. 


\section{Appendix A: Results for the information leadership metric}

Table A.1

Estimates of the information leadership metric for various structural model parameterizations

This table reports means and standard deviations (in parentheses) of information leadership (IL) estimated on 1,000 samples of simulated data. The distribution of the $I L$ estimates in the 1,000 samples approximates the sampling distribution of the $I L$ metric and therefore the reported mean and standard deviation are Monte Carlo estimates of the sampling distribution's mean and the estimator's standard error. The simulated data are generated using the following model:

$$
m_{t}=m_{t-1}+u_{t}, \quad u_{t} \sim \mathrm{N}(0,1), \quad p_{1, t}=m_{t-5}+s_{1, t}, \quad s_{1, t} \sim \mathrm{N}(0,5), \quad p_{2, t}=m_{t-\delta_{2}}+s_{2, t}, \quad s_{2, t} \sim \mathrm{N}\left(0, \sigma_{s_{2}}\right),
$$

where $m_{t}, p_{1, t}$, and $p_{2, t}$ are the natural $\operatorname{logs}$ of fundamental value, price series 1 and price series 2 , respectively, at time $t$. The structural parameters of $p_{1, t}$ are fixed. The structural parameters of $p_{2, t}$ vary: rows correspond to different values of the delay in $p_{2, t}, \delta_{2}$, and columns correspond to different values of the noise in $p_{2, t}, \sigma_{s_{2}}$. For every parameter combination (every cell in the table) 1,000 samples of 21,600 time-series observations are simulated, the information leadership metric for $p_{2, t}\left(I L_{2}\right)$ is estimated for every sample, and finally the mean and standard deviation are calculated across the 1,000 samples. Bold is used to indicate rows/columns in which the delay/noise of $p_{2, t}$ is equal to that of $p_{1, t}$. Grey shading is used to indicate $I L_{2}$ estimates that are greater than 1 .

\begin{tabular}{cccccccccccc}
\hline & & & & \multicolumn{1}{c}{$\sigma_{s_{2}}$} & & & & & \\
\cline { 2 - 12 }$\delta_{2}$ & 0 & 1 & 2 & 3 & 4 & $\mathbf{5}$ & 6 & 7 & 8 & 9 & 10 \\
\hline \multirow{2}{*}{10} & 0.14 & 0.19 & 0.25 & 0.29 & 0.32 & $\mathbf{0 . 3 3}$ & 0.34 & 0.36 & 0.36 & 0.37 & 0.37 \\
& $(0.01)$ & $(0.01)$ & $(0.02)$ & $(0.02)$ & $(0.03)$ & $\mathbf{( 0 . 0 3 )}$ & $(0.04)$ & $(0.04)$ & $(0.05)$ & $(0.05)$ & $(0.05)$ \\
& 0.17 & 0.24 & 0.31 & 0.36 & 0.39 & $\mathbf{0 . 4 1}$ & 0.42 & 0.43 & 0.44 & 0.45 & 0.45 \\
& $(0.01)$ & $(0.01)$ & $(0.02)$ & $(0.02)$ & $(0.03)$ & $\mathbf{( 0 . 0 3 )}$ & $(0.04)$ & $(0.04)$ & $(0.05)$ & $(0.05)$ & $(0.06)$ \\
& 0.22 & 0.31 & 0.40 & 0.45 & 0.48 & $\mathbf{0 . 5 0}$ & 0.52 & 0.53 & 0.54 & 0.55 & 0.55 \\
8 & $(0.01)$ & $(0.02)$ & $(0.02)$ & $(0.03)$ & $(0.03)$ & $\mathbf{( 0 . 0 3 )}$ & $(0.04)$ & $(0.04)$ & $(0.05)$ & $(0.06)$ & $(0.06)$ \\
& 0.30 & 0.41 & 0.51 & 0.57 & 0.60 & $\mathbf{0 . 6 3}$ & 0.64 & 0.65 & 0.66 & 0.67 & 0.67 \\
7 & $(0.02)$ & $(0.02)$ & $(0.03)$ & $(0.03)$ & $(0.03)$ & $\mathbf{( 0 . 0 4 )}$ & $(0.04)$ & $(0.05)$ & $(0.05)$ & $(0.06)$ & $(0.06)$ \\
& 0.40 & 0.55 & 0.67 & 0.73 & 0.77 & $\mathbf{0 . 7 9}$ & 0.80 & 0.81 & 0.81 & 0.82 & 0.82 \\
6 & $(0.02)$ & $(0.03)$ & $(0.04)$ & $(0.04)$ & $(0.04)$ & $\mathbf{( 0 . 0 5 )}$ & $(0.05)$ & $(0.05)$ & $(0.06)$ & $(0.06)$ & $(0.07)$ \\
& $\mathbf{0 . 2 8}$ & $\mathbf{0 . 6 6}$ & $\mathbf{0 . 9 1}$ & $\mathbf{0 . 9 7}$ & $\mathbf{0 . 9 9}$ & $\mathbf{1 . 0 0}$ & $\mathbf{1 . 0 1}$ & $\mathbf{1 . 0 1}$ & $\mathbf{1 . 0 1}$ & $\mathbf{1 . 0 1}$ & $\mathbf{1 . 0 1}$ \\
$\mathbf{5}$ & $\mathbf{( 0 . 3 0 )}$ & $\mathbf{( 0 . 0 4 )}$ & $\mathbf{( 0 . 0 5 )}$ & $\mathbf{( 0 . 0 5 )}$ & $\mathbf{( 0 . 0 5 )}$ & $\mathbf{( 0 . 0 6 )}$ & $\mathbf{( 0 . 0 6 )}$ & $(\mathbf{0 . 0 6 )}$ & $(\mathbf{0 . 0 6 )}$ & $\mathbf{( 0 . 0 7 )}$ & $(\mathbf{0 . 0 7 )}$ \\
& 15.38 & 1.61 & 1.49 & 1.38 & 1.32 & $\mathbf{1 . 2 8}$ & 1.25 & 1.24 & 1.23 & 1.22 & 1.22 \\
4 & $(31.54)$ & $(0.72)$ & $(0.12)$ & $(0.10)$ & $(0.08)$ & $\mathbf{( 0 . 0 7 )}$ & $(0.07)$ & $(0.07)$ & $(0.07)$ & $(0.07)$ & $(0.08)$ \\
& 19.91 & 7.65 & 2.45 & 1.94 & 1.71 & $\mathbf{1 . 6 1}$ & 1.54 & 1.49 & 1.46 & 1.44 & 1.43 \\
3 & $(107.29)$ & $(7.90)$ & $(0.32)$ & $(0.18)$ & $(0.12)$ & $\mathbf{( 0 . 1 0 )}$ & $(0.09)$ & $(0.09)$ & $(0.08)$ & $(0.08)$ & $(0.09)$ \\
& 15.32 & 18.16 & 4.08 & 2.72 & 2.24 & $\mathbf{2 . 0 0}$ & 1.86 & 1.78 & 1.73 & 1.69 & 1.65 \\
2 & $(27.80)$ & $(23.07)$ & $(1.73)$ & $(0.34)$ & $(0.19)$ & $\mathbf{( 0 . 1 4 )}$ & $(0.12)$ & $(0.11)$ & $(0.10)$ & $(0.10)$ & $(0.10)$ \\
& 20.69 & 24.69 & 8.10 & 3.85 & 2.91 & $\mathbf{2 . 4 7}$ & 2.23 & 2.10 & 2.01 & 1.95 & 1.90 \\
1 & $(97.63)$ & $(35.51)$ & $(8.57)$ & $(0.64)$ & $(0.32)$ & $\mathbf{( 0 . 2 0 )}$ & $(0.15)$ & $(0.13)$ & $(0.12)$ & $(0.11)$ & $(0.11)$ \\
& 19.51 & 28.42 & 18.00 & 5.40 & 3.74 & $\mathbf{3 . 0 5}$ & 2.68 & 2.45 & 2.31 & 2.23 & 2.16 \\
0 & $(79.65)$ & $(50.68)$ & $(34.28)$ & $(1.30)$ & $(0.52)$ & $\mathbf{( 0 . 2 9 )}$ & $(0.20)$ & $(0.16)$ & $(0.14)$ & $(0.13)$ & $(0.12)$ \\
\hline
\end{tabular}




\section{Table 1}

\section{Estimates of component shares for various structural model parameterizations}

This table reports means and standard deviations (in parentheses) of component shares $(C S)$ estimated on 1,000 samples of simulated data. The distribution of the $C S$ estimates in the 1,000 samples approximates the sampling distribution of the CS metric and therefore the reported mean and standard deviation are Monte Carlo estimates of the sampling distribution's mean and the estimator's standard error. The simulated data are generated using the following model:

$$
m_{t}=m_{t-1}+u_{t}, \quad u_{t} \sim \mathrm{N}(0,1), \quad p_{1, t}=m_{t-5}+s_{1, t}, \quad s_{1, t} \sim \mathrm{N}(0,5), \quad p_{2, t}=m_{t-\delta_{2}}+s_{2, t}, \quad s_{2, t} \sim \mathrm{N}\left(0, \sigma_{s_{2}}\right),
$$

where $m_{t}, p_{1, t}$, and $p_{2, t}$ are the natural logs of fundamental value, price series 1 and price series 2 , respectively, at time $t$. The structural parameters of $p_{1, t}$ are fixed. The structural parameters of $p_{2, t}$ vary: rows correspond to different values of the delay in $p_{2, t}, \delta_{2}$, and columns correspond to different values of the noise in $p_{2, t}, \sigma_{s_{2}}$. For every parameter combination (every cell in the table) 1,000 samples of 21,600 time-series observations are simulated, the component share of $p_{2, t}\left(C S_{2}\right)$ is estimated for every sample, and finally the mean and standard deviation are calculated across the 1,000 samples. Bold is used to indicate rows/columns in which the delay/noise of $p_{2, t}$ is equal to that of $p_{1, t}$. Grey shading is used to indicate $C S_{2}$ estimates that are greater than 0.5 .

\begin{tabular}{|c|c|c|c|c|c|c|c|c|c|c|c|}
\hline \multirow[b]{2}{*}{$\delta_{2}$} & \multicolumn{11}{|c|}{$\sigma_{s_{2}}$} \\
\hline & 0 & 1 & 2 & 3 & 4 & 5 & 6 & 7 & 8 & 9 & 10 \\
\hline 10 & $\begin{array}{c}0.81 \\
(0.01)\end{array}$ & $\begin{array}{c}0.69 \\
(0.02)\end{array}$ & $\begin{array}{c}0.53 \\
(0.02)\end{array}$ & $\begin{array}{c}0.40 \\
(0.02)\end{array}$ & $\begin{array}{c}0.30 \\
(0.02)\end{array}$ & $\begin{array}{c}0.23 \\
(0.02)\end{array}$ & $\begin{array}{c}0.18 \\
(0.02)\end{array}$ & $\begin{array}{c}0.15 \\
(0.02)\end{array}$ & $\begin{array}{c}0.12 \\
(0.02)\end{array}$ & $\begin{array}{c}0.10 \\
(0.02)\end{array}$ & $\begin{array}{c}0.08 \\
(0.01)\end{array}$ \\
\hline 9 & $\begin{array}{c}0.85 \\
(0.01)\end{array}$ & $\begin{array}{c}0.74 \\
(0.01)\end{array}$ & $\begin{array}{c}0.59 \\
(0.02)\end{array}$ & $\begin{array}{c}0.45 \\
(0.02)\end{array}$ & $\begin{array}{c}0.35 \\
(0.02)\end{array}$ & $\begin{array}{c}0.27 \\
(0.02)\end{array}$ & $\begin{array}{c}0.22 \\
(0.02)\end{array}$ & $\begin{array}{c}0.17 \\
(0.02)\end{array}$ & $\begin{array}{c}0.14 \\
(0.02)\end{array}$ & $\begin{array}{c}0.12 \\
(0.02)\end{array}$ & $\begin{array}{c}0.10 \\
(0.01)\end{array}$ \\
\hline 8 & $\begin{array}{c}0.89 \\
(0.01)\end{array}$ & $\begin{array}{c}0.80 \\
(0.01)\end{array}$ & $\begin{array}{c}0.65 \\
(0.02)\end{array}$ & $\begin{array}{c}0.52 \\
(0.02)\end{array}$ & $\begin{array}{c}0.40 \\
(0.02)\end{array}$ & $\begin{array}{c}0.32 \\
(0.02)\end{array}$ & $\begin{array}{c}0.25 \\
(0.02)\end{array}$ & $\begin{array}{c}0.20 \\
(0.02)\end{array}$ & $\begin{array}{c}0.17 \\
(0.02)\end{array}$ & $\begin{array}{c}0.14 \\
(0.02)\end{array}$ & $\begin{array}{c}0.12 \\
(0.01)\end{array}$ \\
\hline 7 & $\begin{array}{c}0.92 \\
(0.01)\end{array}$ & $\begin{array}{c}0.85 \\
(0.01)\end{array}$ & $\begin{array}{c}0.72 \\
(0.01)\end{array}$ & $\begin{array}{c}0.58 \\
(0.02)\end{array}$ & $\begin{array}{c}0.47 \\
(0.02)\end{array}$ & $\begin{array}{c}0.37 \\
(\mathbf{0 . 0 2})\end{array}$ & $\begin{array}{c}0.30 \\
(0.02)\end{array}$ & $\begin{array}{c}0.24 \\
(0.02)\end{array}$ & $\begin{array}{c}0.20 \\
(0.02)\end{array}$ & $\begin{array}{c}0.17 \\
(0.02)\end{array}$ & $\begin{array}{c}0.14 \\
(0.01)\end{array}$ \\
\hline 6 & $\begin{array}{c}0.96 \\
(0.01)\end{array}$ & $\begin{array}{c}0.90 \\
(0.01)\end{array}$ & $\begin{array}{c}0.79 \\
(0.01)\end{array}$ & $\begin{array}{c}0.65 \\
(0.02)\end{array}$ & $\begin{array}{c}0.53 \\
(0.02)\end{array}$ & $\begin{array}{c}0.43 \\
(0.02)\end{array}$ & $\begin{array}{c}0.35 \\
(0.02)\end{array}$ & $\begin{array}{c}0.29 \\
(0.02)\end{array}$ & $\begin{array}{c}0.24 \\
(0.02)\end{array}$ & $\begin{array}{c}0.20 \\
(0.01)\end{array}$ & $\begin{array}{c}0.17 \\
(0.01)\end{array}$ \\
\hline 5 & $\begin{array}{c}1.00 \\
(0.01)\end{array}$ & $\begin{array}{c}0.96 \\
(0.01)\end{array}$ & $\begin{array}{c}0.86 \\
(0.01)\end{array}$ & $\begin{array}{c}0.74 \\
(0.02)\end{array}$ & $\begin{array}{c}0.61 \\
(0.02)\end{array}$ & $\begin{array}{c}0.50 \\
(0.02)\end{array}$ & $\begin{array}{c}0.41 \\
(0.02)\end{array}$ & $\begin{array}{c}0.34 \\
(0.02)\end{array}$ & $\begin{array}{c}0.28 \\
(0.02)\end{array}$ & $\begin{array}{c}0.24 \\
(0.02)\end{array}$ & $\begin{array}{c}0.20 \\
(\mathbf{0 . 0 1})\end{array}$ \\
\hline 4 & $\begin{array}{c}1.00 \\
(0.01)\end{array}$ & $\begin{array}{c}0.99 \\
(0.01)\end{array}$ & $\begin{array}{c}0.91 \\
(0.01)\end{array}$ & $\begin{array}{c}0.80 \\
(0.02)\end{array}$ & $\begin{array}{c}0.68 \\
(0.02)\end{array}$ & $\begin{array}{c}0.57 \\
(0.02)\end{array}$ & $\begin{array}{c}0.47 \\
(0.02)\end{array}$ & $\begin{array}{c}0.39 \\
(0.02)\end{array}$ & $\begin{array}{c}0.33 \\
(0.02)\end{array}$ & $\begin{array}{c}0.28 \\
(0.01)\end{array}$ & $\begin{array}{c}0.24 \\
(0.01)\end{array}$ \\
\hline 3 & $\begin{array}{c}1.00 \\
(0.01)\end{array}$ & $\begin{array}{c}0.99 \\
(0.01)\end{array}$ & $\begin{array}{c}0.95 \\
(0.01)\end{array}$ & $\begin{array}{c}0.85 \\
(0.02)\end{array}$ & $\begin{array}{c}0.74 \\
(0.02)\end{array}$ & $\begin{array}{c}0.63 \\
(0.02)\end{array}$ & $\begin{array}{c}0.53 \\
(0.02)\end{array}$ & $\begin{array}{c}0.45 \\
(0.02)\end{array}$ & $\begin{array}{c}0.37 \\
(0.02)\end{array}$ & $\begin{array}{c}0.32 \\
(0.01)\end{array}$ & $\begin{array}{c}0.27 \\
(0.01)\end{array}$ \\
\hline 2 & $\begin{array}{c}1.00 \\
(0.01)\end{array}$ & $\begin{array}{c}1.00 \\
(0.01)\end{array}$ & $\begin{array}{c}0.97 \\
(0.02)\end{array}$ & $\begin{array}{c}0.89 \\
(0.02)\end{array}$ & $\begin{array}{c}0.79 \\
(0.02)\end{array}$ & $\begin{array}{c}0.68 \\
(0.02)\end{array}$ & $\begin{array}{c}0.58 \\
(0.02)\end{array}$ & $\begin{array}{c}0.49 \\
(0.02)\end{array}$ & $\begin{array}{c}0.42 \\
(0.02)\end{array}$ & $\begin{array}{c}0.36 \\
(0.02)\end{array}$ & $\begin{array}{c}0.31 \\
(0.01)\end{array}$ \\
\hline 1 & $\begin{array}{c}1.00 \\
(0.01)\end{array}$ & $\begin{array}{c}1.00 \\
(0.01)\end{array}$ & $\begin{array}{c}0.98 \\
(0.01)\end{array}$ & $\begin{array}{c}0.92 \\
(0.02)\end{array}$ & $\begin{array}{c}0.83 \\
(0.02)\end{array}$ & $\begin{array}{c}0.73 \\
(0.02)\end{array}$ & $\begin{array}{c}0.63 \\
(0.02)\end{array}$ & $\begin{array}{c}0.54 \\
(0.02)\end{array}$ & $\begin{array}{c}0.46 \\
(0.02)\end{array}$ & $\begin{array}{c}0.39 \\
(0.02)\end{array}$ & $\begin{array}{c}0.34 \\
(0.01)\end{array}$ \\
\hline 0 & $\begin{array}{r}1.00 \\
(0.01) \\
\end{array}$ & $\begin{array}{c}1.00 \\
(0.01) \\
\end{array}$ & $\begin{array}{c}0.99 \\
(0.01) \\
\end{array}$ & $\begin{array}{c}0.94 \\
(0.02) \\
\end{array}$ & $\begin{array}{c}0.86 \\
(0.02) \\
\end{array}$ & $\begin{array}{c}0.77 \\
(0.02)\end{array}$ & $\begin{array}{c}0.67 \\
(0.02) \\
\end{array}$ & $\begin{array}{c}0.58 \\
(0.02) \\
\end{array}$ & $\begin{array}{c}0.50 \\
(0.02) \\
\end{array}$ & $\begin{array}{c}0.43 \\
(0.02) \\
\end{array}$ & $\begin{array}{c}0.37 \\
(0.01) \\
\end{array}$ \\
\hline
\end{tabular}


Table 2

Estimates of information shares for various structural model parameterizations

This table reports means and standard deviations (in parentheses) of information shares (IS) estimated on 1,000 samples of simulated data. The distribution of the $I S$ estimates in the 1,000 samples approximates the sampling distribution of the $I S$ metric and therefore the reported mean and standard deviation are Monte Carlo estimates of the sampling distribution's mean and the estimator's standard error. The simulated data are generated using the following model:

$$
m_{t}=m_{t-1}+u_{t}, \quad u_{t} \sim \mathrm{N}(0,1), \quad p_{1, t}=m_{t-5}+s_{1, t}, \quad s_{1, t} \sim \mathrm{N}(0,5), \quad p_{2, t}=m_{t-\delta_{2}}+s_{2, t}, \quad s_{2, t} \sim \mathrm{N}\left(0, \sigma_{s_{2}}\right),
$$

where $m_{t}, p_{1, t}$, and $p_{2, t}$ are the natural logs of fundamental value, price series 1 and price series 2 , respectively, at time $t$. The structural parameters of $p_{1, t}$ are fixed. The structural parameters of $p_{2, t}$ vary: rows correspond to different values of the delay in $p_{2, t}, \delta_{2}$, and columns correspond to different values of the noise in $p_{2, t}, \sigma_{s_{2}}$. For every parameter combination (every cell in the table) 1,000 samples of 21,600 time-series observations are simulated, the information share of $p_{2, t}\left(I S_{2}\right)$ is estimated for every sample, and finally the mean and standard deviation are calculated across the 1,000 samples. Bold is used to indicate rows/columns in which the delay/noise of $p_{2, t}$ is equal to that of $p_{1, t}$. Grey shading is used to indicate $I S_{2}$ estimates that are greater than 0.5 .

\begin{tabular}{|c|c|c|c|c|c|c|c|c|c|c|c|}
\hline \multirow[b]{2}{*}{$\delta_{2}$} & \multicolumn{11}{|c|}{$\sigma_{s_{2}}$} \\
\hline & 0 & 1 & 2 & 3 & 4 & 5 & 6 & 7 & 8 & 9 & 10 \\
\hline 10 & $\begin{array}{c}0.37 \\
(0.03)\end{array}$ & $\begin{array}{c}0.30 \\
(0.03)\end{array}$ & $\begin{array}{c}0.22 \\
(0.02)\end{array}$ & $\begin{array}{c}0.16 \\
(0.02)\end{array}$ & $\begin{array}{c}0.12 \\
(0.02)\end{array}$ & $\begin{array}{c}0.09 \\
(0.02)\end{array}$ & $\begin{array}{c}0.07 \\
(0.02)\end{array}$ & $\begin{array}{c}0.06 \\
(0.01)\end{array}$ & $\begin{array}{c}0.05 \\
(0.01)\end{array}$ & $\begin{array}{c}0.04 \\
(0.01)\end{array}$ & $\begin{array}{c}0.03 \\
(0.01)\end{array}$ \\
\hline 9 & $\begin{array}{c}0.49 \\
(0.03)\end{array}$ & $\begin{array}{c}0.41 \\
(0.03)\end{array}$ & $\begin{array}{c}0.31 \\
(0.03)\end{array}$ & $\begin{array}{c}0.23 \\
(0.03)\end{array}$ & $\begin{array}{c}0.17 \\
(0.02)\end{array}$ & $\begin{array}{c}0.13 \\
(0.02)\end{array}$ & $\begin{array}{c}0.11 \\
(0.02)\end{array}$ & $\begin{array}{c}0.08 \\
(0.02)\end{array}$ & $\begin{array}{c}0.07 \\
(0.02)\end{array}$ & $\begin{array}{c}0.06 \\
(0.01)\end{array}$ & $\begin{array}{c}0.05 \\
(0.01)\end{array}$ \\
\hline 8 & $\begin{array}{c}0.64 \\
(0.03)\end{array}$ & $\begin{array}{c}0.55 \\
(0.03)\end{array}$ & $\begin{array}{c}0.43 \\
(0.03)\end{array}$ & $\begin{array}{c}0.32 \\
(0.03)\end{array}$ & $\begin{array}{c}0.25 \\
(0.03)\end{array}$ & $\begin{array}{c}0.19 \\
(0.02)\end{array}$ & $\begin{array}{c}0.15 \\
(0.02)\end{array}$ & $\begin{array}{c}0.12 \\
(0.02)\end{array}$ & $\begin{array}{c}0.10 \\
(0.02)\end{array}$ & $\begin{array}{c}0.08 \\
(0.02)\end{array}$ & $\begin{array}{c}0.07 \\
(0.02)\end{array}$ \\
\hline 7 & $\begin{array}{c}0.79 \\
(0.03)\end{array}$ & $\begin{array}{c}0.70 \\
(0.03)\end{array}$ & $\begin{array}{c}0.56 \\
(0.03)\end{array}$ & $\begin{array}{c}0.44 \\
(0.03)\end{array}$ & $\begin{array}{c}0.34 \\
(0.03)\end{array}$ & $\begin{array}{c}0.27 \\
(0.03)\end{array}$ & $\begin{array}{c}0.21 \\
(0.03)\end{array}$ & $\begin{array}{c}0.17 \\
(0.02)\end{array}$ & $\begin{array}{c}0.14 \\
(0.02)\end{array}$ & $\begin{array}{c}0.12 \\
(0.02)\end{array}$ & $\begin{array}{c}0.10 \\
(0.02)\end{array}$ \\
\hline 6 & $\begin{array}{c}0.91 \\
(0.02)\end{array}$ & $\begin{array}{c}0.84 \\
(0.02)\end{array}$ & $\begin{array}{c}0.71 \\
(0.03)\end{array}$ & $\begin{array}{c}0.58 \\
(0.03)\end{array}$ & $\begin{array}{c}0.46 \\
(0.03)\end{array}$ & $\begin{array}{c}0.37 \\
(\mathbf{0 . 0 3})\end{array}$ & $\begin{array}{c}0.30 \\
(0.03)\end{array}$ & $\begin{array}{c}0.24 \\
(0.03)\end{array}$ & $\begin{array}{c}0.20 \\
(0.02)\end{array}$ & $\begin{array}{c}0.17 \\
(0.02)\end{array}$ & $\begin{array}{c}0.14 \\
(0.02)\end{array}$ \\
\hline 5 & $\begin{array}{c}0.98 \\
(0.01)\end{array}$ & $\begin{array}{c}0.94 \\
(0.01)\end{array}$ & $\begin{array}{c}0.85 \\
(0.02)\end{array}$ & $\begin{array}{c}0.73 \\
(0.03)\end{array}$ & $\begin{array}{c}0.61 \\
(0.03)\end{array}$ & $\begin{array}{c}0.50 \\
(0.03)\end{array}$ & $\begin{array}{c}0.41 \\
(0.03)\end{array}$ & $\begin{array}{c}0.34 \\
(0.03)\end{array}$ & $\begin{array}{c}0.28 \\
(0.03)\end{array}$ & $\begin{array}{c}0.24 \\
(0.03)\end{array}$ & $\begin{array}{c}0.20 \\
(0.02)\end{array}$ \\
\hline 4 & $\begin{array}{c}1.00 \\
(0.00)\end{array}$ & $\begin{array}{c}0.99 \\
(0.01)\end{array}$ & $\begin{array}{c}0.94 \\
(0.01)\end{array}$ & $\begin{array}{c}0.85 \\
(0.02)\end{array}$ & $\begin{array}{c}0.74 \\
(0.03)\end{array}$ & $\begin{array}{c}0.63 \\
(0.03)\end{array}$ & $\begin{array}{c}0.53 \\
(0.03)\end{array}$ & $\begin{array}{c}0.45 \\
(0.03)\end{array}$ & $\begin{array}{c}0.38 \\
(0.03)\end{array}$ & $\begin{array}{c}0.32 \\
(0.03)\end{array}$ & $\begin{array}{c}0.27 \\
(0.03)\end{array}$ \\
\hline 3 & $\begin{array}{c}1.00 \\
(0.00)\end{array}$ & $\begin{array}{c}1.00 \\
(0.00)\end{array}$ & $\begin{array}{c}0.98 \\
(0.01)\end{array}$ & $\begin{array}{c}0.92 \\
(0.02)\end{array}$ & $\begin{array}{c}0.83 \\
(0.02)\end{array}$ & $\begin{array}{c}0.73 \\
(0.03)\end{array}$ & $\begin{array}{c}0.63 \\
(0.03)\end{array}$ & $\begin{array}{c}0.54 \\
(0.03)\end{array}$ & $\begin{array}{c}0.47 \\
(0.03)\end{array}$ & $\begin{array}{c}0.40 \\
(0.03)\end{array}$ & $\begin{array}{c}0.35 \\
(0.03)\end{array}$ \\
\hline 2 & $\begin{array}{c}1.00 \\
(0.00)\end{array}$ & $\begin{array}{c}1.00 \\
(0.00)\end{array}$ & $\begin{array}{c}0.99 \\
(0.01)\end{array}$ & $\begin{array}{c}0.96 \\
(0.01)\end{array}$ & $\begin{array}{c}0.89 \\
(0.02)\end{array}$ & $\begin{array}{c}0.81 \\
(0.02)\end{array}$ & $\begin{array}{c}0.72 \\
(0.03)\end{array}$ & $\begin{array}{c}0.63 \\
(0.03)\end{array}$ & $\begin{array}{c}0.55 \\
(0.03)\end{array}$ & $\begin{array}{c}0.48 \\
(0.03)\end{array}$ & $\begin{array}{c}0.42 \\
(0.03)\end{array}$ \\
\hline 1 & $\begin{array}{c}1.00 \\
(0.00)\end{array}$ & $\begin{array}{c}1.00 \\
(0.00)\end{array}$ & $\begin{array}{c}1.00 \\
(0.00)\end{array}$ & $\begin{array}{c}0.98 \\
(0.01)\end{array}$ & $\begin{array}{c}0.93 \\
(0.02)\end{array}$ & $\begin{array}{c}0.87 \\
(0.02)\end{array}$ & $\begin{array}{c}0.79 \\
(0.02)\end{array}$ & $\begin{array}{c}0.71 \\
(0.03)\end{array}$ & $\begin{array}{c}0.63 \\
(0.03)\end{array}$ & $\begin{array}{c}0.56 \\
(0.03)\end{array}$ & $\begin{array}{c}0.49 \\
(0.03)\end{array}$ \\
\hline 0 & $\begin{array}{c}1.00 \\
(0.00)\end{array}$ & $\begin{array}{c}1.00 \\
(0.00)\end{array}$ & $\begin{array}{c}1.00 \\
(0.00)\end{array}$ & $\begin{array}{c}0.99 \\
(0.01)\end{array}$ & $\begin{array}{c}0.96 \\
(0.01)\end{array}$ & $\begin{array}{c}0.91 \\
(0.02)\end{array}$ & $\begin{array}{c}0.84 \\
(0.02)\end{array}$ & $\begin{array}{c}0.77 \\
(0.03)\end{array}$ & $\begin{array}{c}0.69 \\
(0.03)\end{array}$ & $\begin{array}{c}0.62 \\
(0.03)\end{array}$ & $\begin{array}{c}0.56 \\
(0.03)\end{array}$ \\
\hline
\end{tabular}


Table 3

Estimates of information leadership shares for various structural model parameterizations

This table reports means and standard deviations (in parentheses) of information leadership shares (ILS) estimated on 1,000 samples of simulated data. The distribution of the ILS estimates in the 1,000 samples approximates the sampling distribution of the $I L S$ metric and therefore the reported mean and standard deviation are Monte Carlo estimates of the sampling distribution's mean and the estimator's standard error. The simulated data are generated using the following model:

$$
m_{t}=m_{t-1}+u_{t}, \quad u_{t} \sim \mathrm{N}(0,1), \quad p_{1, t}=m_{t-5}+s_{1, t}, \quad s_{1, t} \sim \mathrm{N}(0,5), \quad p_{2, t}=m_{t-\delta_{2}}+s_{2, t}, \quad s_{2, t} \sim \mathrm{N}\left(0, \sigma_{s_{2}}\right),
$$

where $m_{t}, p_{1, t}$, and $p_{2, t}$ are the natural logs of fundamental value, price series 1 and price series 2 , respectively, at time $t$. The structural parameters of $p_{1, t}$ are fixed. The structural parameters of $p_{2, t}$ vary: rows correspond to different values of the delay in $p_{2, t}, \delta_{2}$, and columns correspond to different values of the noise in $p_{2, t}, \sigma_{s_{2}}$. For every parameter combination (every cell in the table) 1,000 samples of 21,600 time-series observations are simulated, the information leadership share of $p_{2, t}\left(I L S_{2}\right)$ is estimated for every sample, and finally the mean and standard deviation are calculated across the 1,000 samples. Bold is used to indicate rows/columns in which the delay/noise of $p_{2, t}$ is equal to that of $p_{1, t}$. Grey shading is used to indicate $I L S_{2}$ estimates that are greater than 0.5 .

\begin{tabular}{|c|c|c|c|c|c|c|c|c|c|c|c|}
\hline \multirow[b]{2}{*}{$\delta_{2}$} & \multicolumn{11}{|c|}{$\sigma_{s_{2}}$} \\
\hline & 0 & 1 & 2 & 3 & 4 & 5 & 6 & 7 & 8 & 9 & 10 \\
\hline 10 & $\begin{array}{c}0.02 \\
(0.00)\end{array}$ & $\begin{array}{c}0.04 \\
(0.00)\end{array}$ & $\begin{array}{c}0.06 \\
(0.01)\end{array}$ & $\begin{array}{c}0.08 \\
(0.01)\end{array}$ & $\begin{array}{c}0.09 \\
(0.01)\end{array}$ & $\begin{array}{c}0.10 \\
(0.02)\end{array}$ & $\begin{array}{c}0.11 \\
(0.02)\end{array}$ & $\begin{array}{c}0.11 \\
(0.02)\end{array}$ & $\begin{array}{c}0.12 \\
(0.03)\end{array}$ & $\begin{array}{c}0.12 \\
(0.03)\end{array}$ & $\begin{array}{c}0.12 \\
(0.03)\end{array}$ \\
\hline 9 & $\begin{array}{c}0.03 \\
(0.00)\end{array}$ & $\begin{array}{c}0.06 \\
(0.01)\end{array}$ & $\begin{array}{c}0.09 \\
(0.01)\end{array}$ & $\begin{array}{c}0.11 \\
(0.01)\end{array}$ & $\begin{array}{c}0.13 \\
(0.02)\end{array}$ & $\begin{array}{c}0.14 \\
(0.02)\end{array}$ & $\begin{array}{c}0.15 \\
(0.02)\end{array}$ & $\begin{array}{c}0.16 \\
(0.03)\end{array}$ & $\begin{array}{c}0.16 \\
(0.03)\end{array}$ & $\begin{array}{c}0.17 \\
(0.03)\end{array}$ & $\begin{array}{c}0.17 \\
(0.04)\end{array}$ \\
\hline 8 & $\begin{array}{c}0.05 \\
(0.00)\end{array}$ & $\begin{array}{c}0.09 \\
(0.01)\end{array}$ & $\begin{array}{c}0.14 \\
(0.01)\end{array}$ & $\begin{array}{c}0.17 \\
(0.02)\end{array}$ & $\begin{array}{c}0.19 \\
(0.02)\end{array}$ & $\begin{array}{c}0.20 \\
(0.02)\end{array}$ & $\begin{array}{c}0.21 \\
(0.03)\end{array}$ & $\begin{array}{c}0.22 \\
(0.03)\end{array}$ & $\begin{array}{c}0.23 \\
(0.03)\end{array}$ & $\begin{array}{c}0.23 \\
(0.04)\end{array}$ & $\begin{array}{c}0.23 \\
(0.04)\end{array}$ \\
\hline 7 & $\begin{array}{c}0.08 \\
(0.01)\end{array}$ & $\begin{array}{c}0.14 \\
(0.01)\end{array}$ & $\begin{array}{c}0.21 \\
(0.02)\end{array}$ & $\begin{array}{c}0.24 \\
(0.02)\end{array}$ & $\begin{array}{c}0.27 \\
(0.02)\end{array}$ & $\begin{array}{c}0.28 \\
(0.02)\end{array}$ & $\begin{array}{c}0.29 \\
(0.03)\end{array}$ & $\begin{array}{c}0.30 \\
(0.03)\end{array}$ & $\begin{array}{c}0.30 \\
(0.03)\end{array}$ & $\begin{array}{c}0.31 \\
(0.04)\end{array}$ & $\begin{array}{c}0.31 \\
(0.04)\end{array}$ \\
\hline 6 & $\begin{array}{c}0.14 \\
(0.01)\end{array}$ & $\begin{array}{c}0.23 \\
(0.02)\end{array}$ & $\begin{array}{c}0.31 \\
(0.02)\end{array}$ & $\begin{array}{c}0.35 \\
(0.02)\end{array}$ & $\begin{array}{c}0.37 \\
(0.02)\end{array}$ & $\begin{array}{c}0.38 \\
(0.03)\end{array}$ & $\begin{array}{c}0.39 \\
(0.03)\end{array}$ & $\begin{array}{c}0.39 \\
(0.03)\end{array}$ & $\begin{array}{c}0.40 \\
(0.03)\end{array}$ & $\begin{array}{c}0.40 \\
(0.04)\end{array}$ & $\begin{array}{c}0.40 \\
(0.04)\end{array}$ \\
\hline 5 & $\begin{array}{c}0.10 \\
(0.15)\end{array}$ & $\begin{array}{c}0.31 \\
(0.03)\end{array}$ & $\begin{array}{c}0.45 \\
(0.03)\end{array}$ & $\begin{array}{c}0.48 \\
(0.03)\end{array}$ & $\begin{array}{c}0.50 \\
(0.03)\end{array}$ & $\begin{array}{c}0.50 \\
(0.03)\end{array}$ & $\begin{array}{c}0.50 \\
(0.03)\end{array}$ & $\begin{array}{c}0.50 \\
(0.03)\end{array}$ & $\begin{array}{c}0.51 \\
(0.03)\end{array}$ & $\begin{array}{c}0.51 \\
(0.03)\end{array}$ & $\begin{array}{c}0.50 \\
(0.03)\end{array}$ \\
\hline 4 & $\begin{array}{c}0.97 \\
(0.07)\end{array}$ & $\begin{array}{c}0.68 \\
(0.17)\end{array}$ & $\begin{array}{c}0.69 \\
(0.03)\end{array}$ & $\begin{array}{c}0.65 \\
(0.03)\end{array}$ & $\begin{array}{c}0.63 \\
(0.03)\end{array}$ & $\begin{array}{c}0.62 \\
(0.03)\end{array}$ & $\begin{array}{c}0.61 \\
(0.03)\end{array}$ & $\begin{array}{c}0.60 \\
(0.03)\end{array}$ & $\begin{array}{c}0.60 \\
(0.03)\end{array}$ & $\begin{array}{c}0.60 \\
(0.03)\end{array}$ & $\begin{array}{c}0.60 \\
(0.03)\end{array}$ \\
\hline 3 & $\begin{array}{c}0.97 \\
(0.08)\end{array}$ & $\begin{array}{c}0.93 \\
(0.11)\end{array}$ & $\begin{array}{c}0.85 \\
(0.04)\end{array}$ & $\begin{array}{c}0.79 \\
(0.03)\end{array}$ & $\begin{array}{c}0.74 \\
(0.03)\end{array}$ & $\begin{array}{c}0.72 \\
(0.03)\end{array}$ & $\begin{array}{c}0.70 \\
(0.02)\end{array}$ & $\begin{array}{c}0.69 \\
(0.02)\end{array}$ & $\begin{array}{c}0.68 \\
(0.02)\end{array}$ & $\begin{array}{c}0.67 \\
(0.02)\end{array}$ & $\begin{array}{c}0.67 \\
(0.03)\end{array}$ \\
\hline 2 & $\begin{array}{c}0.97 \\
(0.06)\end{array}$ & $\begin{array}{c}0.98 \\
(0.08)\end{array}$ & $\begin{array}{c}0.93 \\
(0.06)\end{array}$ & $\begin{array}{c}0.88 \\
(0.03)\end{array}$ & $\begin{array}{c}0.83 \\
(0.02)\end{array}$ & $\begin{array}{c}0.80 \\
(0.02)\end{array}$ & $\begin{array}{c}0.77 \\
(0.02)\end{array}$ & $\begin{array}{c}0.76 \\
(0.02)\end{array}$ & $\begin{array}{c}0.75 \\
(0.02)\end{array}$ & $\begin{array}{c}0.74 \\
(0.02)\end{array}$ & $\begin{array}{c}0.73 \\
(0.02)\end{array}$ \\
\hline 1 & $\begin{array}{c}0.97 \\
(0.06)\end{array}$ & $\begin{array}{c}0.99 \\
(0.05)\end{array}$ & $\begin{array}{c}0.96 \\
(0.07)\end{array}$ & $\begin{array}{c}0.93 \\
(0.02)\end{array}$ & $\begin{array}{c}0.89 \\
(0.02)\end{array}$ & $\begin{array}{c}0.86 \\
(0.02)\end{array}$ & $\begin{array}{c}0.83 \\
(0.02)\end{array}$ & $\begin{array}{c}0.81 \\
(0.02)\end{array}$ & $\begin{array}{c}0.80 \\
(0.02)\end{array}$ & $\begin{array}{c}0.79 \\
(0.02)\end{array}$ & $\begin{array}{c}0.78 \\
(0.02)\end{array}$ \\
\hline 0 & $\begin{array}{c}0.97 \\
(0.07)\end{array}$ & $\begin{array}{c}0.99 \\
(0.03)\end{array}$ & $\begin{array}{c}0.98 \\
(0.07)\end{array}$ & $\begin{array}{c}0.96 \\
(0.02)\end{array}$ & $\begin{array}{c}0.93 \\
(0.02)\end{array}$ & $\begin{array}{c}0.90 \\
(0.02)\end{array}$ & $\begin{array}{c}0.88 \\
(0.02)\end{array}$ & $\begin{array}{c}0.86 \\
(0.02)\end{array}$ & $\begin{array}{c}0.84 \\
(0.02)\end{array}$ & $\begin{array}{c}0.83 \\
(0.02)\end{array}$ & $\begin{array}{c}0.82 \\
(0.02)\end{array}$ \\
\hline
\end{tabular}


Table 4

Estimates of price discovery shares for four existing studies

This table reports information shares (IS) and component shares (CS) from four existing studies of price discovery. The last two columns report our estimates of the information leadership shares (ILS) calculated from the given IS and $C S$ values. In Panel A, 5-year and 10-year refer to the 5-year and 10-year US Treasury notes and the price discovery metrics are reported for the futures market (relative to the spot market). In Panel B the underlying traded asset is EU Allowances in the EU Emissions Trading Scheme; 2008 and 2009 refer to the contracts with maturity December 2009 and December 2009, respectively; $10 \mathrm{~min}$ and $30 \mathrm{~min}$ refer to 10 minute and 30 minute sampling frequencies; and the price discovery metrics are reported for the futures market (relative to the spot market). In Panel $\mathrm{C}$ the underlying financial instrument is the Taiwan Stock Index; $P C P$ and $B S$ refer to the put-call-parity and Black-Scholes methods of calculating implied spot prices; and the price discovery metrics are reported for the futures market (relative to the options market). In Panel D the underlying instruments are currency pairs; the categories such as 08:20-10:00 refer to intraday periods of time; and the price discovery metrics are reported for the spot market (relative to the futures market).

\begin{tabular}{|c|c|c|c|}
\hline & IS & $\mathrm{CS}$ & ILS \\
\hline \multicolumn{4}{|c|}{ Panel A: Mizrach and Neely (2008) } \\
\hline 5-year & Futures & Futures & Futures \\
\hline 1995 & 0.59 & 0.75 & 0.18 \\
\hline 1996 & 0.58 & 0.77 & 0.13 \\
\hline 1997 & 0.51 & 0.75 & 0.11 \\
\hline 1998 & 0.28 & 0.67 & 0.05 \\
\hline 1999 & 0.39 & 0.67 & 0.10 \\
\hline 2000 & 0.51 & 0.70 & 0.16 \\
\hline 2001 & 0.73 & 0.79 & 0.35 \\
\hline \multicolumn{4}{|l|}{ 10-year } \\
\hline 1995 & 0.72 & 0.80 & 0.29 \\
\hline 1996 & 0.72 & 0.80 & 0.28 \\
\hline 1997 & 0.70 & 0.78 & 0.30 \\
\hline 1998 & 0.50 & 0.73 & 0.12 \\
\hline 1999 & 0.61 & 0.78 & 0.17 \\
\hline 2000 & 0.71 & 0.82 & 0.23 \\
\hline 2001 & 0.83 & 0.85 & 0.41 \\
\hline \multicolumn{4}{|c|}{ Panel B: Rittler (2012) } \\
\hline Full sample & Futures & Futures & Futures \\
\hline $10 \mathrm{~min}$ & 0.69 & 0.72 & 0.42 \\
\hline $30 \mathrm{~min}$ & 0.58 & 0.73 & 0.21 \\
\hline \multicolumn{4}{|l|}{2008} \\
\hline $10 \mathrm{~min}$ & 0.65 & 0.59 & 0.63 \\
\hline $30 \mathrm{~min}$ & 0.52 & 0.51 & 0.52 \\
\hline \multicolumn{4}{|l|}{2009} \\
\hline $10 \mathrm{~min}$ & 0.69 & 0.80 & 0.23 \\
\hline $30 \mathrm{~min}$ & 0.60 & 0.91 & 0.02 \\
\hline \multicolumn{4}{|c|}{ Panel C: Hsieh et al. (2008) } \\
\hline & Futures & Futures & Futures \\
\hline PCP & 0.66 & 0.83 & 0.14 \\
\hline $\mathrm{BS}$ & 0.50 & 0.81 & 0.05 \\
\hline
\end{tabular}


Table 4 (continued)

\begin{tabular}{|c|c|c|c|}
\hline & IS & $\mathrm{CS}$ & ILS \\
\hline \multicolumn{4}{|c|}{ Panel D: Chen and Gau (2010) } \\
\hline JPY-USD & Spot & Spot & Spot \\
\hline Full sample & 0.67 & 0.72 & 0.38 \\
\hline 08:20-10:00 & 0.61 & 0.61 & 0.49 \\
\hline $10: 01-11: 40$ & 0.62 & 0.65 & 0.45 \\
\hline $11: 41-13: 20$ & 0.66 & 0.65 & 0.52 \\
\hline $13: 21-15: 00$ & 0.69 & 0.72 & 0.43 \\
\hline \multicolumn{4}{|l|}{ EUR-USD } \\
\hline Full sample & 0.63 & 0.69 & 0.36 \\
\hline 08:20-10:00 & 0.54 & 0.52 & 0.53 \\
\hline $10: 01-11: 40$ & 0.54 & 0.55 & 0.48 \\
\hline $11: 41-13: 20$ & 0.56 & 0.55 & 0.52 \\
\hline $13: 21-15: 00$ & 0.60 & 0.58 & 0.54 \\
\hline
\end{tabular}




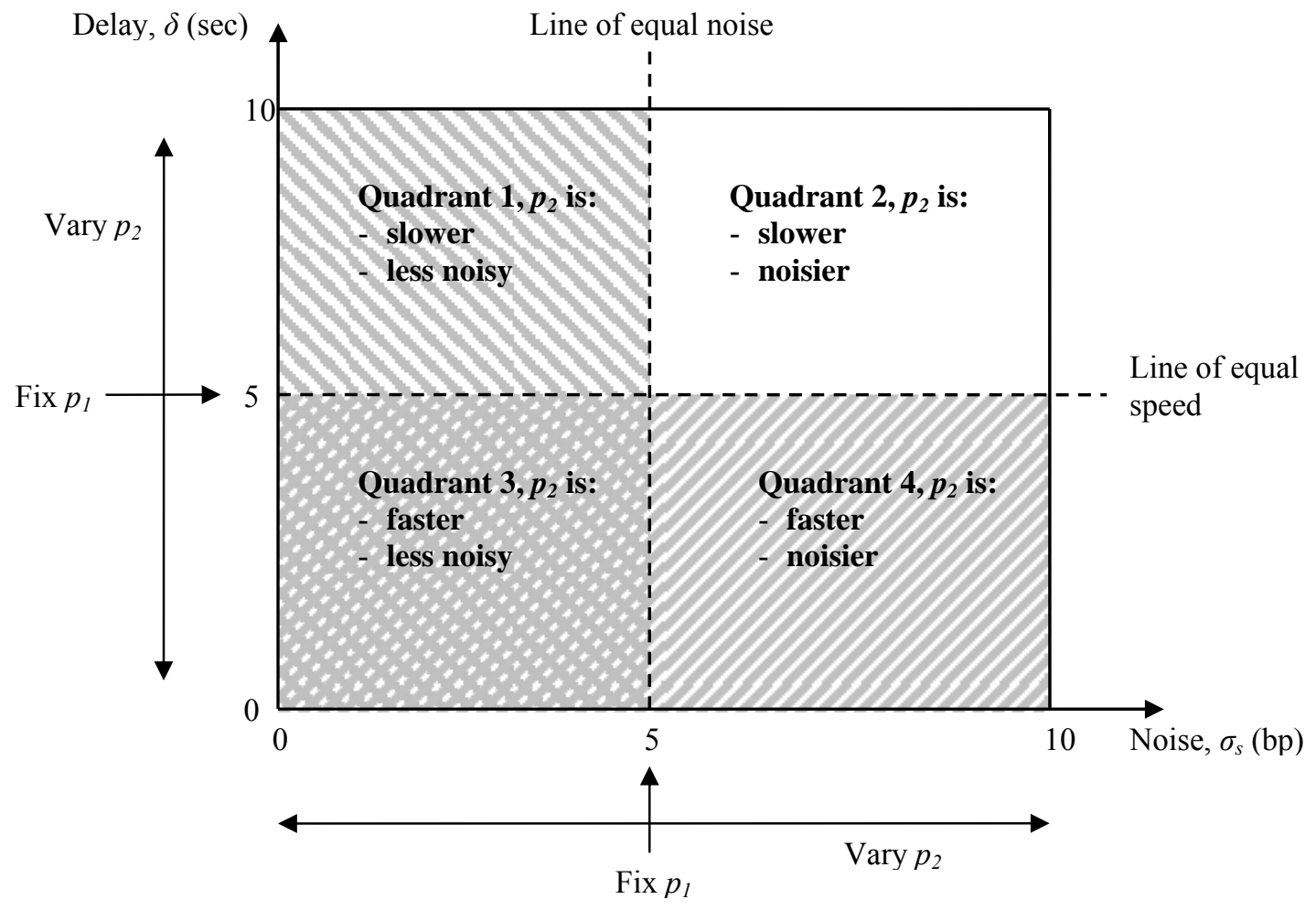

Figure 1. Grid of structural model parameter combinations used in simulations. 
Quadrant 1: $p_{2}$ is slower but less noisy than $p_{1}$

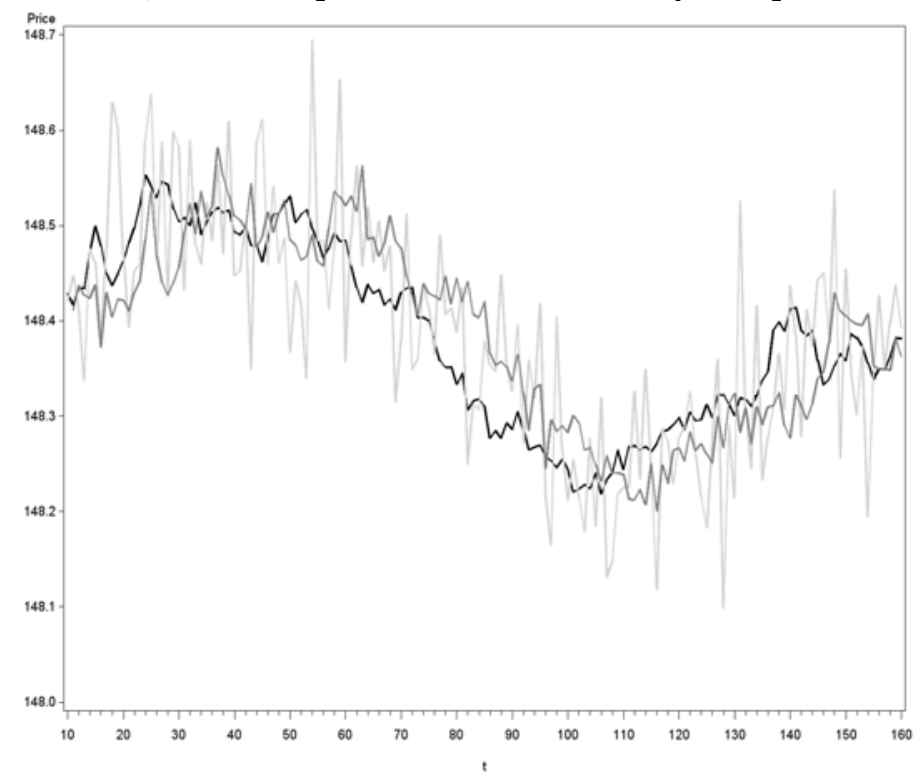

Quadrant 3: $p_{2}$ is faster and less noisy than $p_{1}$

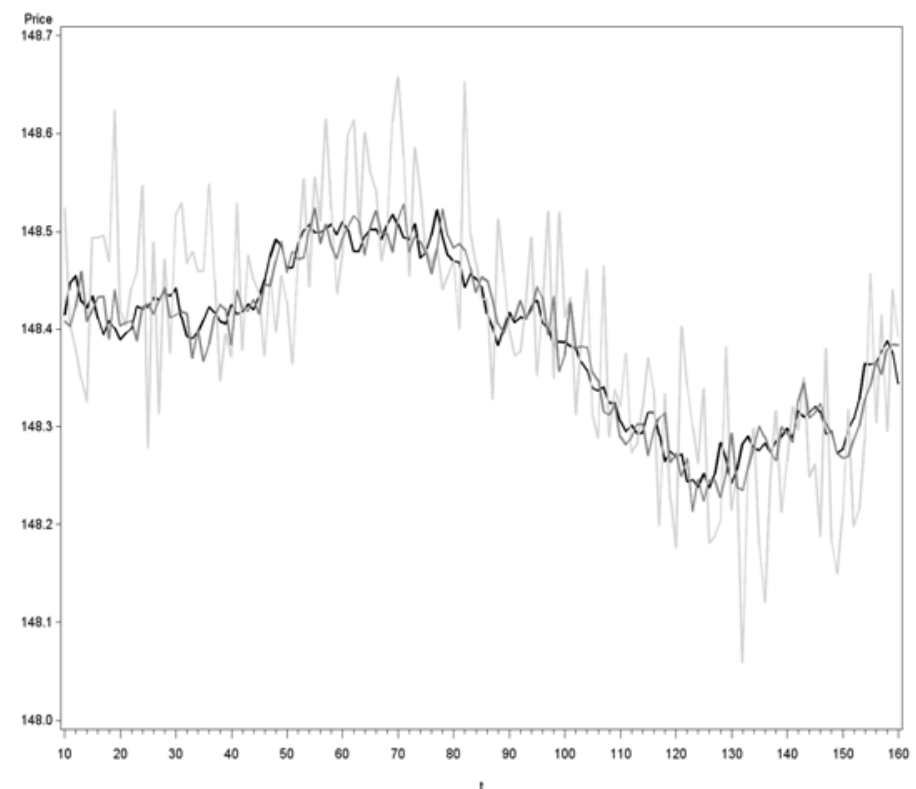

Quadrant 2: $p_{2}$ is slower and noisier than $p_{1}$

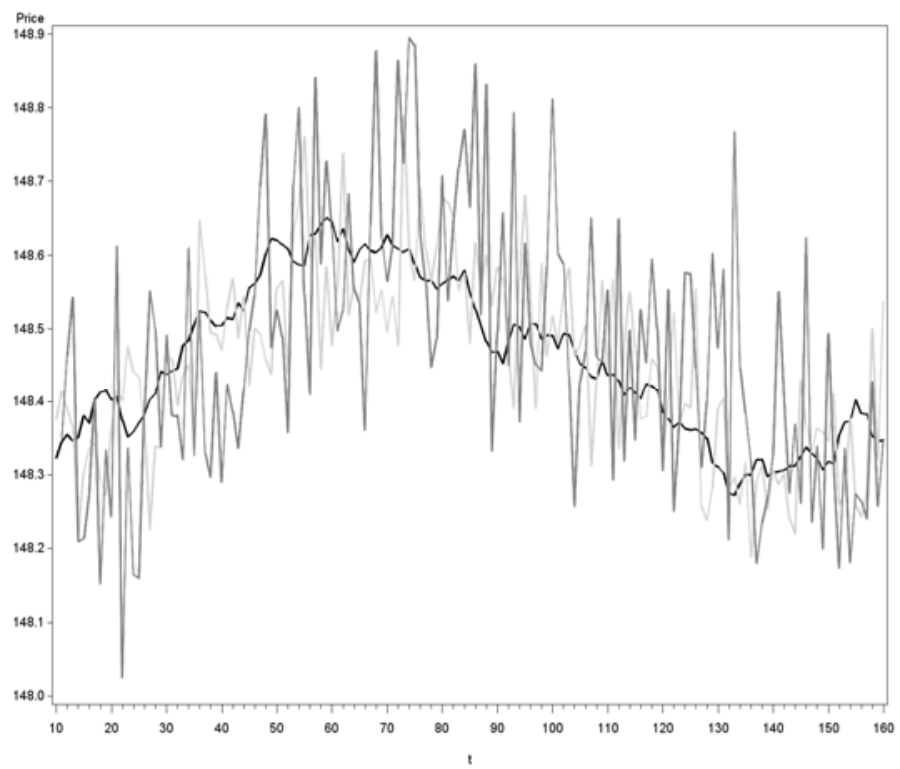

Quadrant 4: $p_{2}$ is faster but noisier than $p_{1}$

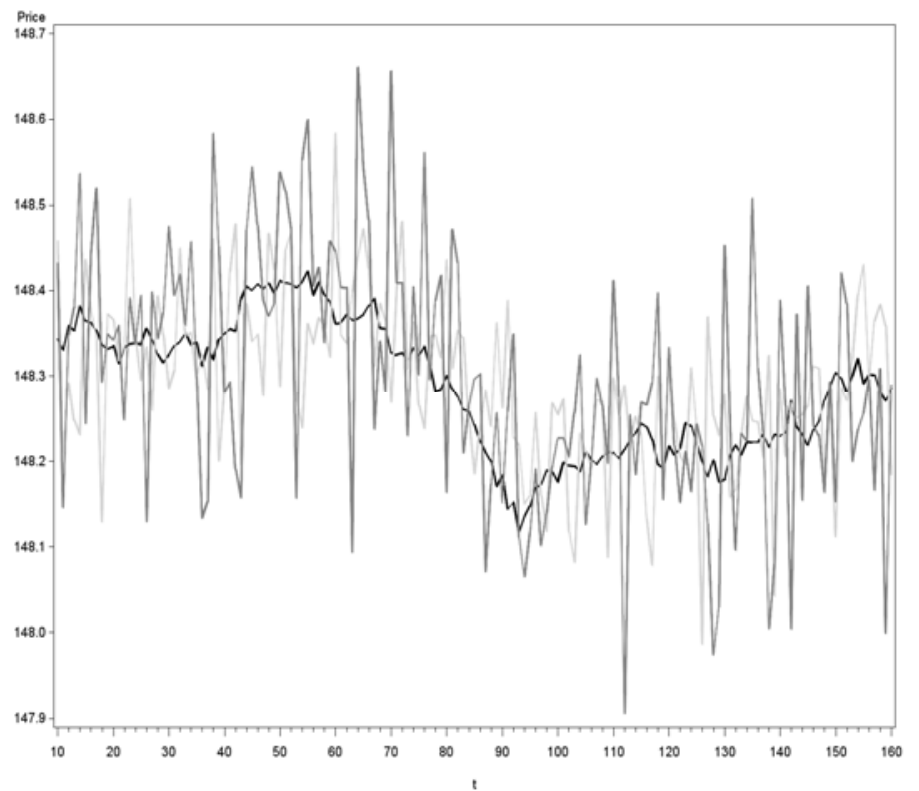

Figure 2. Samples of simulated data for four parameter combinations. The darkest line is the common fundamental value, the next darkest is the price series of interest $\left(p_{2}\right)$ and the lightest line is the reference price series $\left(p_{1}\right)$. The simulated data are generated using the following model:

$$
m_{t}=m_{t-1}+u_{t}, \quad u_{t} \sim \mathrm{N}(0,1), \quad p_{1, t}=m_{t-5}+s_{1, t}, \quad s_{1, t} \sim \mathrm{N}(0,5), \quad p_{2, t}=m_{t-\delta_{2}}+s_{2, t}, \quad s_{2, t} \sim \mathrm{N}\left(0, \sigma_{s_{2}}\right),
$$

where $m_{t}, p_{1, t}$, and $p_{2, t}$ are the natural logs of fundamental value, price series 1 and price series 2, respectively, at time $t$ (the plotted values are not in logs). For the plots in this Figure we set the following parameters: $\delta_{2}=10, \sigma_{s_{2}}=1$ (Quadrant 1); $\delta_{2}=10, \sigma_{s_{2}}=9$ (Quadrant 2); $\delta_{2}=1, \sigma_{s_{2}}=1$ (Quadrant 3); and $\delta_{2}=1, \sigma_{s_{2}}=9$ (Quadrant 4). 